\title{
Non-invasive Multimodality
} Cardiovascular Imaging of the Right Heart and Pulmonary Circulation in Pulmonary Hypertension

\section{OPEN ACCESS}

Edited by:

Tim Lahm,

Indiana University, United States

Reviewed by:

Harm Bogaard,

VU University Medical Center

Netherlands

Kenichi Hongo,

Jikei University School of Medicine,

Japan

*Correspondence:

David J. Hur

david.hur@yale.edu

Specialty section:

This article was submitted to Heart Failure and Transplantation,

a section of the journal

Frontiers in Cardiovascular Medicine

Received: 14 October 2018

Accepted: 20 February 2019

Published: 14 March 2019

Citation:

Hur DJ and Sugeng L (2019)

Non-invasive Multimodality Cardiovascular Imaging of the Right Heart and Pulmonary Circulation in

Pulmonary Hypertension.

Front. Cardiovasc. Med. 6:24.

doi: 10.3389/fcvm.2019.00024

\author{
David J. Hur ${ }^{1,2 *}$ and Lissa Sugeng ${ }^{1,3}$ \\ ${ }^{1}$ Section of Cardiovascular Medicine, Department of Internal Medicine, Yale School of Medicine, New Haven, CT, \\ United States, ${ }^{2}$ Division of Cardiology, Department of Medicine, Veterans Affairs Connecticut Healthcare System, West \\ Haven, CT, United States, ${ }^{3}$ Echocardiography Laboratory, Yale New Haven Hospital, New Haven, CT, United States
}

Pulmonary hypertension $(\mathrm{PH})$ is defined as resting mean pulmonary arterial pressure $(\mathrm{mPAP}) \geq 25$ millimeters of mercury $(\mathrm{mmHg})$ via right heart $(\mathrm{RH})$ catheterization $(\mathrm{RHC})$, where increased afterload in the pulmonary arterial vasculature leads to alterations in $\mathrm{RH}$ structure and function. Mortality rates have remained high despite therapy, however non-invasive imaging holds the potential to expedite diagnosis and lead to earlier initiation of treatment, with the hope of improving prognosis. While historically the right ventricle (RV) had been considered a passive chamber with minimal role in the overall function of the heart, in recent years in the evaluation of $\mathrm{PH}$ and $\mathrm{RH}$ failure the anatomical and functional assessment of the RV has received increased attention regarding its performance and its relationship to other structures in the RH-pulmonary circulation. Today, the RV is the key determinant of patient survival. This review provides an overview and summary of non-invasive imaging methods to assess RV structure, function, flow, and tissue characterization in the setting of imaging's contribution to the diagnostic, severity stratification, prognostic risk, response of treatment management, and disease surveillance implications of $\mathrm{PH}$ 's impact on $\mathrm{RH}$ dysfunction and clinical $\mathrm{RH}$ failure.

Keywords: pulmonary hypertension, right heart, non-invasive imaging, multimodality, echocardiography, nuclear cardiology, computed tomography, magnetic resonance

\section{INTRODUCTION}

Pulmonary hypertension $(\mathrm{PH})$ is a progressive, potentially life-threatening condition resulting from a variety of causes, defined as an invasively measured resting mean pulmonary arterial pressure (mPAP) $\geq 25 \mathrm{mmHg}(1)$. The resultant increased afterload in the pulmonary circulation as a result of extensive proliferation and remodeling in the pulmonary artery (PA) vasculature (2) leads to alterations in right heart (RH) structure and function. According to the World Symposium on Pulmonary Hypertension (3), five groups have been defined (Figure 1): group 1 as pulmonary arterial hypertension (PAH), group 2 as $\mathrm{PH}$ due to left heart (LH) disease, group 3 as $\mathrm{PH}$ due to lung disease and/or hypoxia, group 4 as chronic thromboembolic pulmonary hypertension (CTEPH), and group 5 as PH from other causes; PH can be characterized further by involvement at the precapillary and/or post-capillary level. The assessment of $\mathrm{PH}$ is based on a comprehensive appraisal of the clinical history, physical examination, and diagnostic studies. However, diagnosis of PH and its subsequent treatment is frequently delayed, as clinical symptoms often overlap with common diseases of the cardiovascular (CV) and respiratory systems (5). The result of often determining $\mathrm{PH}$ late in the disease course is that mortality rates have remained high despite therapy (6). 
Goals of non-invasive imaging in $\mathrm{PH}$ have been focused on helping to establish the diagnosis sooner and identify contributing disease group(s). The need for earlier diagnosis and intervention has been supported, for example, by the finding that PAH patients in World Health Organization functional class (WHO FC) I or II have better long-term survival than those with more severe impairment (WHO FC III or IV) $(7,8)$. The hope of expediting correct group classification of etiology is that delineating the underlying cause will impact on prognosis and management (3), and ultimately coming to an early, accurate diagnosis of $\mathrm{PH}$ may allow for earlier treatment and the chance for improved outcomes $(9,10)$. Historically, the 6-min walk test has been used to monitor the effects of treatment on $\mathrm{PH}$ (11). However, in a meta-analysis involving more than 20 clinical trials showed that the 6-min walk test was not predictive of outcomes (12). Thus, there has been an ongoing push to elucidate other quantitative and imaging-based markers of $\mathrm{PH}$ severity that can be used to document response to therapy, both for use in clinical trials and ultimately with the aim for real-world practice.

\section{Approach to PH Evaluation Using Imaging}

Right ventricular failure is frequently the cause of death in PH $(13,14)$. Thus, the historical view that the right ventricle (RV) being a passive chamber with minimal role in the overall function of the heart has changed in recent years, particularly in the evaluation of $\mathrm{PH}$. This has given rise to increasing attention and focus on the RV regarding its performance and relationship to other structures in the $\mathrm{RH}$-pulmonary circulation, including the PA, tricuspid valve (TV), and right atrium (RA).

\footnotetext{
Abbreviations: 2D, two-dimensional; 3D, three-dimensional; 4D, fourdimensional; AAo, ascending aorta; AVM, arteriovenous malformation; BSA, body surface area; $\mathrm{CHD}$, congenital heart disease; CMR, cardiovascular magnetic resonance imaging; COPD, chronic obstructive pulmonary disease; CSA, crosssectional area; CTEPH, chronic thromboembolic pulmonary hypertension; $\mathrm{CT}$, computed tomography; CTA, computed tomographic angiography; CTPA, computed tomographic pulmonary angiography; $\mathrm{CV}$, cardiovascular; CXR, chest radiography; DCE, dynamic contrast-enhanced; DE, delayed enhancement; DECT, dual-energy computed tomography; DS, dual-source; $\Delta \mathrm{P}$, peak pressure gradient; ECG, electrocardiogram; EF, ejection fraction; ePLAR, echocardiographic pulmonary to left atrial ratio; FAC, fractional area change; FHS, Framingham Heart Study; GBCA, gadolinium-based contrast agent; HR, high-resolution; IV, intravenous; IVS, interventricular septum; IVC, inferior vena cava; LH, left heart; $\mathrm{LV}$, left ventricle; $\mathrm{MD}$, multidetector; $\mathrm{mmHg}$, millimeters of mercury; $\mathrm{MPA}$, main pulmonary artery; mPAP, mean pulmonary arterial pressure; MRA, magnetic resonance angiography; MRI, magnetic resonance imaging; $\mathrm{mSv}$, milliSieverts; $\mathrm{m} / \mathrm{s}$, meters per second; PA, pulmonary artery; PADP, pulmonary artery diastolic pressure; $\mathrm{PAH}$, pulmonary arterial hypertension; PASP, pulmonary artery systolic pressure; PBV, pulmonary blood volume; PC, phase contrast; $\mathrm{PCH}$, pulmonary capillary hemangiomatosis; PE, pulmonary embolism; PET, positron emission tomography; $\mathrm{PH}$, pulmonary hypertension; PRI, perfusion redistribution index; PVOD, pulmonary veno-occlusive disease; Qp:Qs, pulmonary-to-systemic flow ratio; RA, right atrium; RAC, relative area change; $\mathrm{RAP}$, right atrial pressure; RCA, right coronary artery; RH, right heart; RHC, right heart catheterization; RIMP, right ventricular myocardial performance index; RV, right ventricle; RVSP, right ventricular systolic pressure; SD, standard deviation; SPECT, single-photon emission computed tomography; SV, stroke volume; $S$, systolic velocity of tricuspid valve annulus; SSFP, steady-state free precession; TAPSE, tricuspid annular plane systolic excursion; TR, tricuspid valve insufficiency; TRjetV, trans-tricuspid valvular regurgitant jet velocity; TTE, transthoracic echocardiography; TV, tricuspid valve; V/Q, ventilation/perfusion; WHO FC, World Health Organization functional class; WSS, wall shear stress.
}

The shape of the RV is more complex than that of the left ventricle (LV). The RV has superficial circumferential muscle fibers responsible for an inward bellows movement of the free wall contracting toward the rigid septum, as well as inner longitudinal fibers that result in the base-to-apex contraction movement (15). Compared to the LV, the base-to-apex shortening provides a greater contribution to RV emptying (16). RV function is a reflection of mechanical coupling between the RV and PA (17). Due to its shape and location, as well as the load dependence of the ejection fraction (EF), accurate evaluation of $\mathrm{RV}$ function remains challenging. The various imaging modalities, with differing degrees of sensitivity and specificity, provide incremental, often complementary information. This review provides an overview and summary of the current noninvasive imaging methods to assess RV structure, function, flow, and tissue characterization. Emerging evidence and established guidelines are discussed in the setting of imaging's contribution to diagnosis, severity stratification, prognostic risk, treatment management response, and disease surveillance of $\mathrm{PH}$ and its impact on RH dysfunction and clinical RH failure. The utility, advantages, and limitations of the imaging modalities that are used to evaluate the RV in patients with suspected or known $\mathrm{PH}$ will be discussed. Table 1 summarizes the strengths and limitations of the various imaging techniques. With the aim of value-based decision-making, a judicious step-wise approach algorithm to utilization of imaging in $\mathrm{PH}$ evaluation may reduce unnecessary testing and improve the value of care (Figure 2).

\section{INITIAL EVALUATION OF THE PATIENT REFERRED FOR PREVIOUSLY UNEXPLAINED DYSPNEA OR SUSPECTED PH}

The initial evaluation of individuals with unelucidated causes of shortness of breath should involve chest radiography (CXR) and transthoracic echocardiography (TTE).

\section{Chest Radiography}

CXR (Figure 3) is usually part of the initial or baseline evaluation of patients with unexplained shortness of breath or other symptoms that could be due to $\mathrm{PH}$. It remains widely used due to availability and relatively low cost. It can depict features of $\mathrm{PH}$ that are indicative of the underlying cause, such as lung abnormalities in patients with $\mathrm{PAH}$ secondary to systemic sclerosis (group 1), PH secondary to lung parenchymal diseases, such as emphysema or interstitial lung disease (group 3), or PH secondary to CTEPH (group 4) in the setting of sign(s) of pulmonary embolism (Westermark's sign, a wedge-shaped shadow indicating pulmonary infarction, or Hampton's hump, a wedge-shaped opacification secondary to pulmonary hemorrhage).

Chest plain X-ray films can uncover significant pulmonary vascular abnormalities by showing vessel displacement and changes in vascularity of the lungs (19). While a normal CXR does not necessarily exclude $\mathrm{PH}$ given that it is usually not sensitive for the identification of patients with mild to moderate 


\section{Pulmonary Hypertension (PH) $\mathrm{mPAP} \geq 25 \mathrm{mmHg}$}

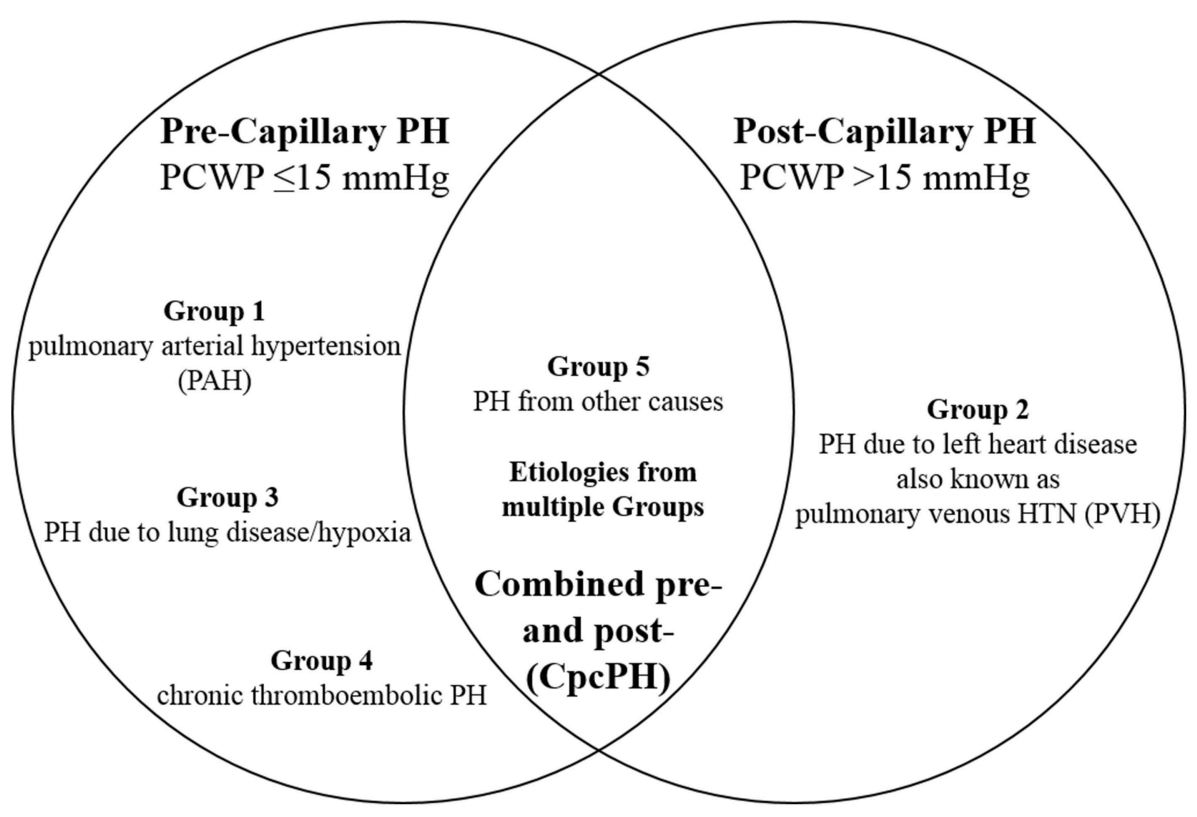

FIGURE 1 | Hemodynamic definitions of pulmonary hypertension $(\mathrm{PH})$ and clinical group classification. Combined pre- and post-capillary pulmonary hypertension $(\mathrm{CpcPH})$ is characterized by pulmonary venous hypertension $(\mathrm{PVH})$, in addition to trans-pulmonary gradient $>7 \mathrm{mmHg}$ or pulmonary vascular resistance $>3$ Wood units. mPAP, mean pulmonary arterial pressure; PCWP, pulmonary capillary wedge pressure. Adapted from Dellegrottaglie et al. (4).

PH (20), it is commonly abnormal in established disease and can detect the typical changes seen in the PAs and $\mathrm{RH}$ in those with longstanding, severe $\mathrm{PH}$ (21). These classic, late findings of $\mathrm{PH}$ on CXR include characteristic dilation of the main and central PAs (22), while the branch PAs and peripheral blood vessels become abruptly tapered, resulting in a pruning appearance (23). Calcific, atherosclerotic changes may be seen along the central PAs (24), and PA-pulmonary vein ratio may be altered; increased ratio suggests arterial $\mathrm{PH}$, whereas decreased ratio indicates venous $\mathrm{PH}$ (25). The CXR can show signs of cardiac involvement as well. The RH may appear enlarged, as suggested by cardiomegaly and prominence of the right border, a result of RA enlargement, on posteroanterior projection and decreased retrosternal air space and obliteration of clear space in the lateral projection, a result of RV dilatation.

\section{Transthoracic Echocardiography}

TTE has a leading role in the $\mathrm{PH}$ guidelines, recommended as a first-line non-invasive imaging test to be performed as part of the initial workup for suspected PH (26). It is safe, widely available, reproducible, and relatively inexpensive (27). Echo is an essential non-invasive cardiac imaging screening tool for determining the presence of $\mathrm{PH}$, especially in those where the condition has high probability to be expected (28). TTE's role is vital in the investigation in determining the most common cause of $\mathrm{PH}$ in the developed world, group 2 ( $\mathrm{PH}$ due to $\mathrm{LH}$ disease); it may also be useful in patients with family history of $\mathrm{PAH}$, congenital heart disease (CHD), systemic to pulmonary shunts, portal hypertension, or systemic diseases associated with $\mathrm{PH}(29,30)$. The modality can provide two- (2D) and in cases with good image quality three-dimensional (3D) information on several parameters in the evaluation for $\mathrm{PH}$. Echo can assess for chamber (RV and RA) size (Figures 4A-C) (31). RV systolic function can be assessed in a variety of ways, including via tricuspid annular plane systolic excursion (TAPSE), Dopplerderived systolic velocity of TV annulus ( $S^{\prime}$ ), fractional area change (FAC), RV myocardial performance (also known as Tei) index (RIMP), RV dP/dt, RVEF, and RV strain $(16,32)$.

TTE also has the capability to assess hemodynamics, such as estimation of pulmonary artery systolic pressure (PASP) from maximum trans-tricuspid valvular regurgitant jet velocity (TRjetV) as determined from continuous-wave Doppler in addition to right atrial pressure (33). The peak pressure gradient $(\Delta P)$ of tricuspid valve insufficiency (TR, Figure 4D) is calculated via the modified Bernoulli equation:

$$
\Delta P=4 \times v^{2},
$$

where $v$ is the Doppler imaging-derived maximal TRjetV in meters per second (m/s) (Figure 4E) (16). The right atrial pressure (RAP) in millimeters of mercury $(\mathrm{mmHg})$ is estimated by quantifying the collapsibility index (34) of the inferior vena cava (IVC), acquired from the subcostal view with the patient in the supine position and measured in the long-axis view $1-2 \mathrm{~cm}$ from the IVC-RA junction, along with an inspiratory sniff (31). The following RAP values have been proposed (35): IVC diameter 
TABLE 1 | Relative strengths and limitations of non-invasive imaging modalities used in pulmonary hypertension.

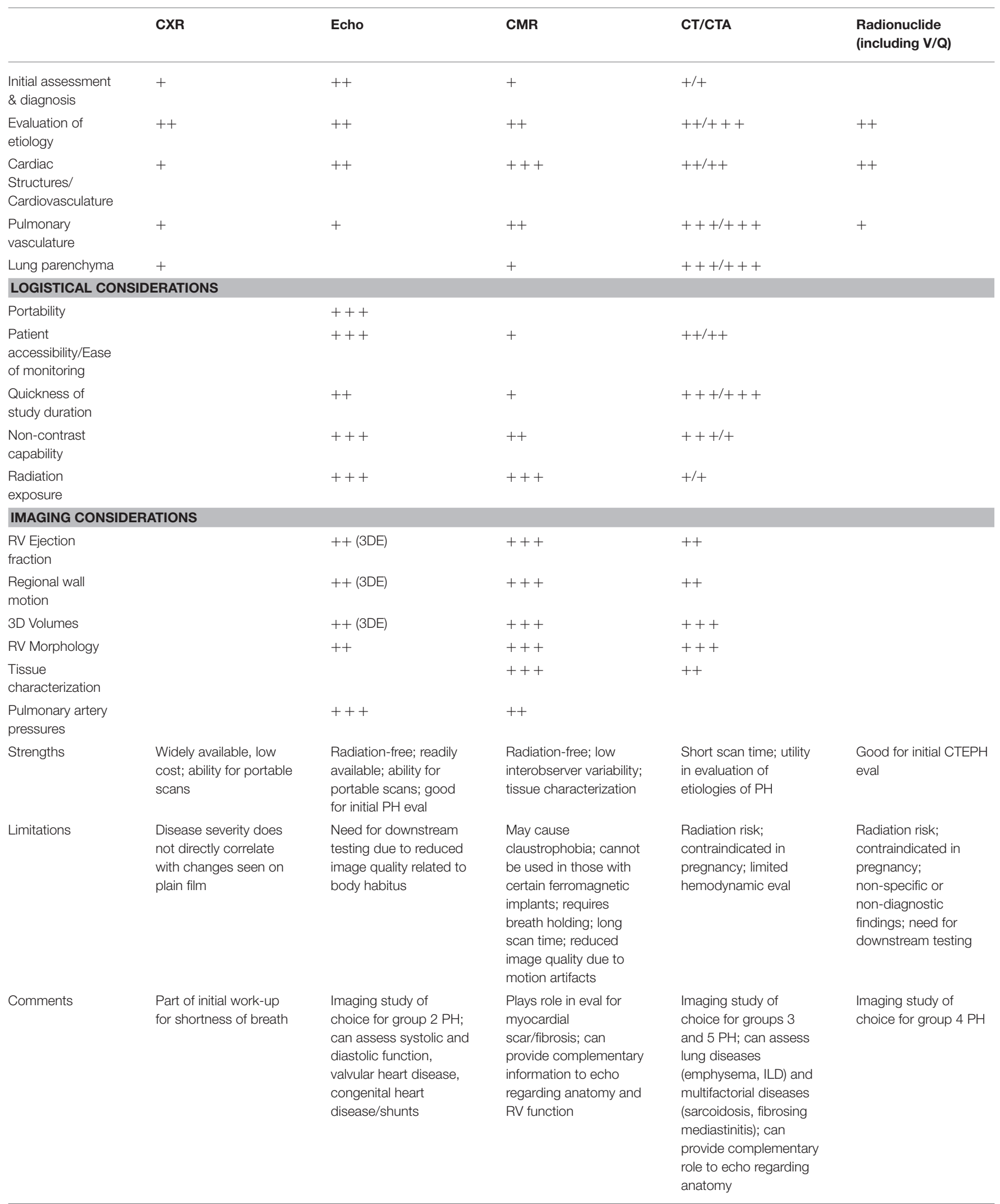

+, limited utility; ++, moderate utility; +++, high utility; 3DE, three-dimensional echocardiography; CMR, cardiac magnetic resonance; CT, computed tomography; CTA, computed tomography angiography; CTEPH, chronic thromboembolic pulmonary hypertension; CXR, chest radiography; ILD, interstitial lung disease; PH, pulmonary hypertension; RV, right ventricular; $V / Q$, ventilation/perfusion scan. 


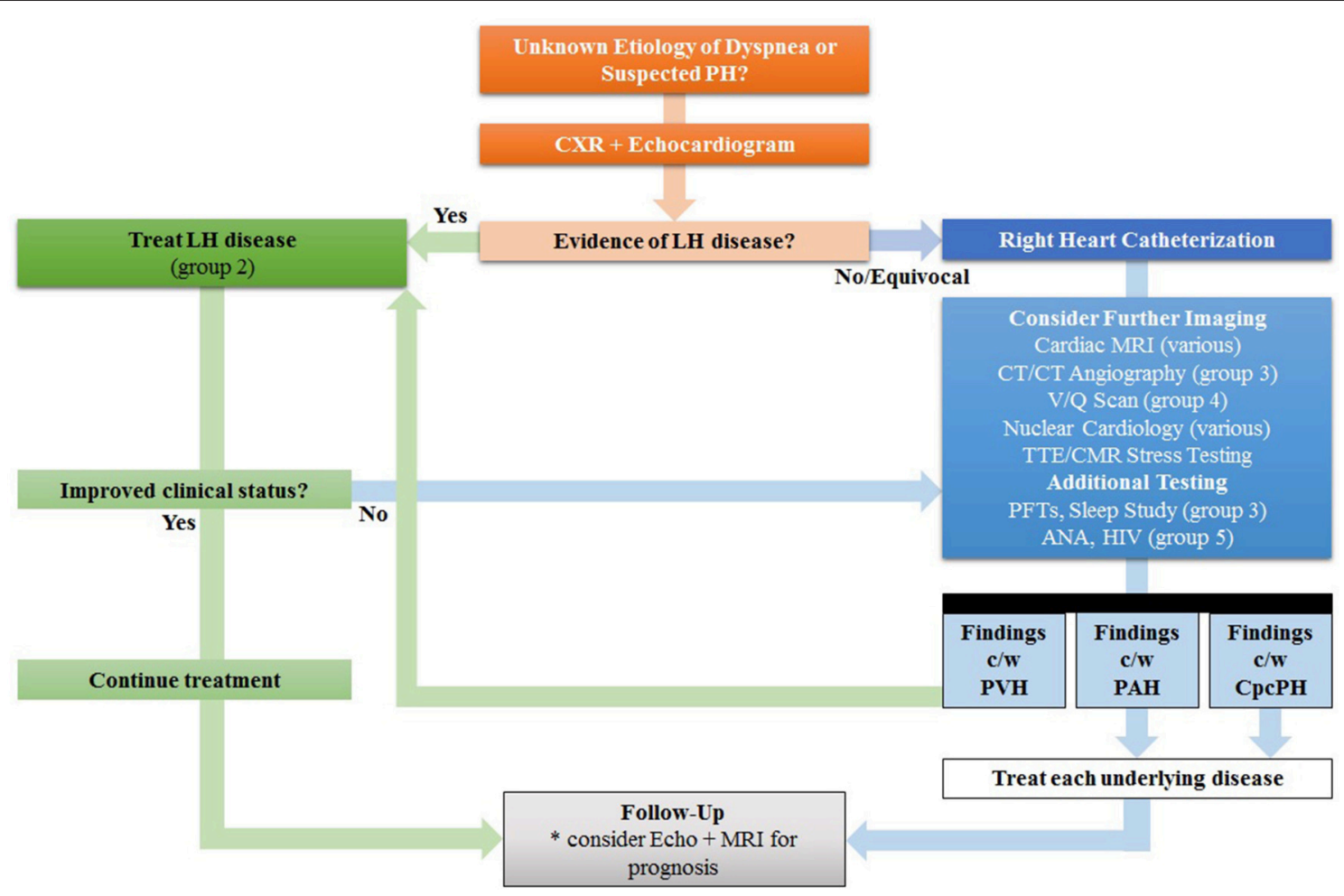

FIGURE 2 | Proposed Step-Wise Approach In Lieu of Traditional "Shotgun" Approach for the evaluation of Pulmonary Hypertension (PH). Since many patients with $\mathrm{PH}$ in the developed world have left heart $(\mathrm{LH})$ disease, the echocardiogram is the preferred test for initial cardiac work-up; if findings are consistent with pulmonary venous hypertension $(\mathrm{PVH})$, treatment for left heart disease is recommended first before automatically proceeding to other tests, such as invasive hemodynamic testing. Other signs of $\mathrm{LH}$ disease include reduced left ventricular ejection fraction, aortic valve disease, and mitral valve disease. Treatment of $\mathrm{LH}$ disease is dependent on the underlying etiology, but in group $2 \mathrm{PH}$ many patients will improve with diuresis and lowering of systemic blood pressure with vasodilators. Further non-invasive imaging or invasive catheterization can be considered as second-line options. MRI can be considered for prognosis and follow-up. ANA, antinuclear antibody, $\mathrm{CpcPH}$, combined pre- and post-capillary pulmonary hypertension; CT, computed tomography; HIV, human immunodeficiency virus; LH, left heart; MRI, magnetic resonance imaging; PAH, pulmonary arterial hypertension; PFTs, pulmonary function tests; V/Q, ventilation/perfusion. Adapted from Freed et al. (18).
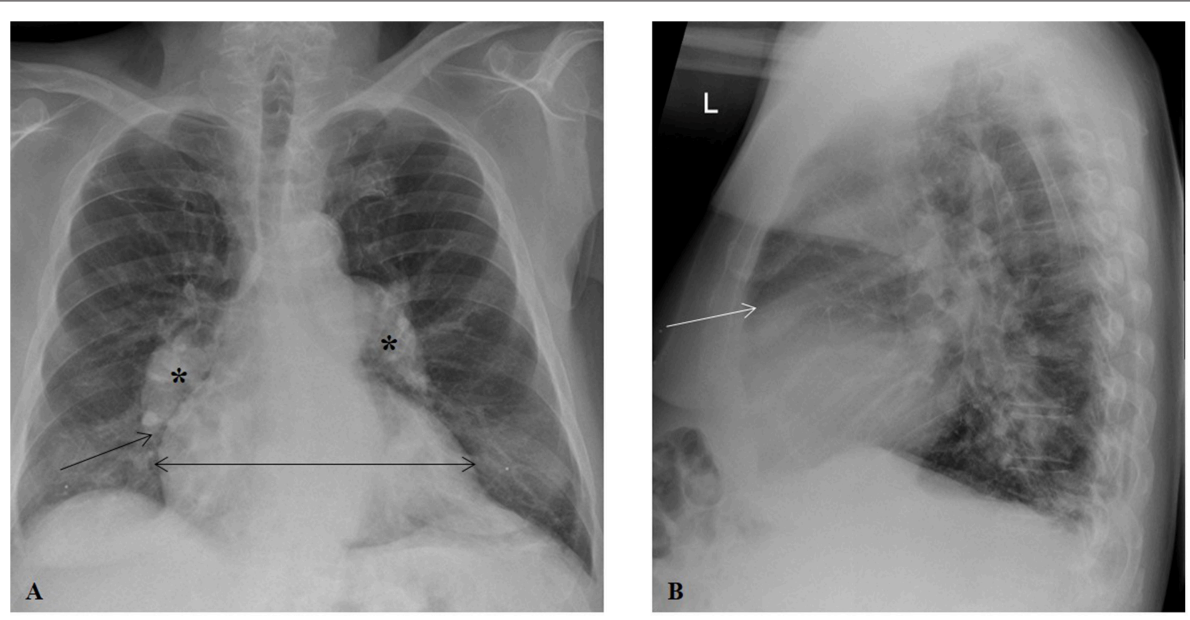

FIGURE 3 | Chest radiography in a patient with groups 2 and 3 pulmonary hypertension. (A) Posteroanterior projection illustrating prominent, dilated central pulmonary arteries (asterisks), cardiomegaly (horizontal line), and rapid tapering (pruning) of right pulmonary artery (arrow). (B) Lateral projection showing a decrease in the retrosternal air space (arrow). 


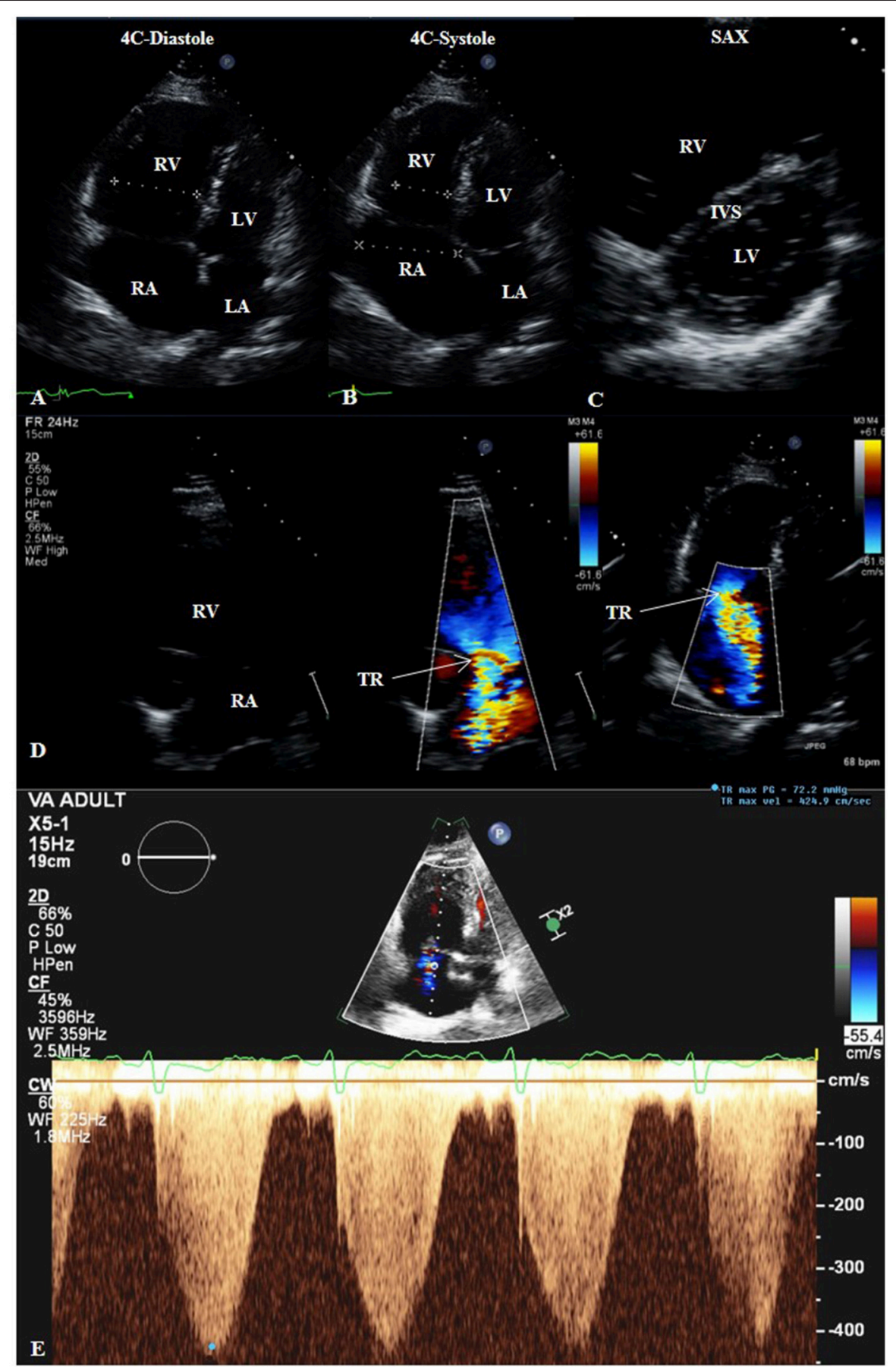

FIGURE 4 | Transthoracic echocardiogram (TTE) of a patient with groups 2 and 3 pulmonary hypertension. 2D TTE in the apical four-chamber (4C) view in diastole (A) and systole (B) showing right heart dilatation. 2D TTE in the short-axis (SAX) view (C) showing flattening of the interventricular septum compatible with the right heart findings. (D) Color-compare TTE in the right ventricular inflow view and color Doppler TTE in the 4C view showing severe tricuspid regurgitation. (E) Continuous-wave Doppler TTE showing maximum trans-tricuspid valvular regurgitant jet velocity of $4.25 \mathrm{~m} / \mathrm{s}$, correlating to estimated pulmonary artery systolic pressure of $72 \mathrm{mmHg}$ plus right atrial pressure. 4C, four-chamber; IVS, interventricular septum; LA, left atrium; LV, left ventricle; RA, right atrium; RV, right ventricle; SAX, short-axis; TR, tricuspid regurgitation.

$<2.1 \mathrm{~cm}$ that collapses $>50 \%$ with a sniff suggests normal RAP of $3 \mathrm{mmHg}$ (range, $0-5 \mathrm{mmHg}$ ), whereas IVC diameter $>2.1 \mathrm{~cm}$ that collapses $<50 \%$ with a sniff suggests high RAP of $15 \mathrm{mmHg}$ (range, 10-20 $\mathrm{mmHg}$ ); in situations in which IVC diameter and collapse do not fit this model, an intermediate value of $8 \mathrm{mmHg}$ (range, $5-10 \mathrm{~mm} \mathrm{Hg}$ ) may be used. $\mathrm{PH}$ is considered possible 
when: (1) TRjetV 2.9-3.4 m/s and PASP 37-50 mmHg, regardless of whether other signs of $\mathrm{PH}$ are present; or (2) TRjetV $\leq 2.8$ $\mathrm{m} / \mathrm{s}, \mathrm{PASP} \leq 36 \mathrm{mmHg}$, but additional echo variables suggestive of $\mathrm{PH}$ are present (33). In their 2015 guidelines for the diagnosis and treatment of $\mathrm{PH}$, the joint task force of the European Society of Cardiology and the European Respiratory Society recommend grading the probability of $\mathrm{PH}$ based on TRjetV at rest and the presence of additional echo variables (PA diameter $>2.5 \mathrm{~cm}$, early diastolic pulmonary regurgitation velocity $>2.2$ $\mathrm{m} / \mathrm{s}$, flattening of the interventricular septum (LV eccentricity index $>1.1$ in systole and/or diastole), RV/LV basal diameter ratio $>1.0$, RV outflow Doppler acceleration time $<105 \mathrm{~ms}$ and/or mid-systolic notching, RA area (end-systole) $>18 \mathrm{~cm}^{2}$, IVC $>2.1 \mathrm{~cm}$ with decreased inspiratory collapse ( $<50 \%$ with a sniff or $<20 \%$ with quiet inspiration) (26). The probability should be considered high if: (1) TRjetV $>3.4 \mathrm{~m} / \mathrm{s}$ (even with no other signs); or (2) TRjetV $\geq 2.9 \mathrm{~m} / \mathrm{s}$ and additional echo variables suggestive of $\mathrm{PH}$ are present. The probability should be considered intermediate if: (1) TRjetV 2.9-3.4 m/s with no other signs; or (2) TRjetV $\leq 2.8 \mathrm{~m} / \mathrm{s}$ (or insufficiently measurable due to trivial envelope), but accompanied by additional signs of $\mathrm{PH}$. The probability can be considered low if TRjetV $\leq 2.8 \mathrm{~m} / \mathrm{s}$ or not measurable, and there are no additional echo variables suggestive of $\mathrm{PH}$. Correlations between echocardiographic Doppler imaging and invasive measurements of PASP are high (36). However, discordance between non-invasive and invasive pressure measurements can occur; causes of inaccurate PA pressure measurement by TTE include poor acoustic windows, Doppler misalignment with the TR jet, interobserver variability in measuring the TRjetV, and breakdown in the assumptions inherent in the modified Bernoulli equation. In the absence of a gradient across the RV outflow tract or pulmonic valve, PASP is equal to RV systolic pressure (RVSP).

Other parameters that can be ascertained by echo include PA diastolic pressure (PADP) and mPAP. PADP can be estimated from the end-diastolic pulmonic regurgitant jet velocity using the continuous-wave Doppler signal of pulmonic insufficiency and modified Bernoulli equation: PADP $=4 \times$ (end-diastolic pulmonic regurgitant jet velocity) ${ }^{2}+$ RAP (16). mPAP can be determined in several ways: $\mathrm{mPAP}=\frac{1}{3}(\mathrm{SPAP})+\frac{2}{3}(\mathrm{PADP})$; or estimated by using pulmonary acceleration time as measured by pulse-wave Doppler of the PA in systole and determined by the following formulas: $\mathrm{mPAP}=79-(0.45 \times$ systolic PA acceleration time $)$ or $90-(0.62 \times$ systolic PA acceleration time $)$ in those with acceleration time less than $120 \mathrm{~ms}$ (37); or correlated to $4 \times$ (early or maximal pulmonic regurgitant jet velocity) ${ }^{2}+$ RAP (38).

Finally, more recently a novel parameter, echocardiographic pulmonary to left atrial ratio (ePLAR) has been described to distinguish between pre-capillary and post-capillary PH (39). ePLAR has been proposed as an echo surrogate for transpulmonary gradient and its interaction with LA pressure: ePLAR $=\mathrm{TRjet}_{\max } /$ (mitral E/e'); values for normal reference population were $0.30 \pm 0.09 \mathrm{~m} / \mathrm{s}$; pre-capillary $\mathrm{PH}$ patients (ePLAR $0.44 \pm 0.22 \mathrm{~m} / \mathrm{s}$ ) had significantly higher values than post-capillary $\mathrm{PH}$ patients (ePLAR $0.20 \pm 0.11 \mathrm{~m} / \mathrm{s}, p<0.001$ ). Combined pre- and post-capillary $\mathrm{PH}$ patients had intermediate values (ePLAR $0.28 \pm 0.18 \mathrm{~m} / \mathrm{s}$ ), but remained significantly higher than in those with isolated post-capillary $\mathrm{PH}$ (those with post-capillary $\mathrm{PH}$ further distinguished from combined by having diastolic pulmonary gradient $<7 \mathrm{mmHg}$; ePLAR $0.18 \pm$ $0.08 \mathrm{~m} / \mathrm{s}, p<0.001)$.

\section{ADVANCED AND ADJUNCT TECHNIQUES}

If there is evidence of LH disease by CXR and echo, the clinician should proceed to treat the LH disease. However, when there is no overt or equivocal evidence of LH disease, further non-invasive imaging should be considered in conjunction with RHC, which may include cardiovascular magnetic resonance (CMR) imaging, computed tomography (CT), and radionuclide studies.

\section{Cardiovascular Magnetic Resonance}

$\mathrm{CMR}$ is a $3 \mathrm{D}$ tomographic technique that, due to high definition of the blood pool-myocardium interface and reproducibility of RV parameters (40) has become the non-invasive reference standard for assessing right-sided chamber sizes, morphology, and myocardial mass, as well as transvalvular flow (41). CMR allows for accurate quantification of RV volumes, mass, and EF $(15,42)$. It is useful in the work-up of cardiomyopathy as it has the potential to detect myocardial inflammation and fibrosis, both ischemic-mediated scar from infarction and non-ischemic scar from infiltrative processes (43). While CMR is expensive, less widely available, and requires operator expertise and high technical demands, including longer scan times, it is safe and does not expose patients to ionizing radiation. Compared to TTE, CMR offers improved spatial resolution not limited by acoustic windows.

CMR scans include cine, phase contrast (PC), and postcontrast sequences. For cine imaging, a four-chamber steadystate free precession (SSFP) cine stack in axial oblique view is typically obtained for the RV. These images are usually obtained at $8-\mathrm{mm}$ slice intervals with a $2-\mathrm{mm}$ inter-slice (25\%) gap. Additionally, a short-axis SSFP cine stack can be obtained. Next, PC imaging of the main, right, and left PAs is obtained to assess peak velocities and differential flow to the right and left lungs. Also, valve regurgitation such as TR severity can be quantified either directly or indirectly. Then, contrast-enhanced magnetic resonance angiography (MRA) can be performed. In patients for whom gadolinium-based contrast agent (GBCA) is contraindicated, non-contrast MRA techniques such as navigator (electrogram [ECG] and respiratory)-gated whole-heart SSFP MRA can be used, although this can be suboptimal for the evaluation of distal segmental and subsegmental vasculature. Finally, delayed enhancement (DE) imaging can be obtained 10-15 min after receipt of intravenous (IV) GBCA, permitting visualization of myocardial scar.

\section{CMR Techniques for RH Structure, Function, and Tissue Characterization}

CMR allows for additional valuable characterization of the $\mathrm{RH}$ in patients with $\mathrm{PH}$, providing information on $\mathrm{RV}$ size, morphology, volumes, interventricular septum (IVS) shape, and function (44), as well as RV mass $(45,46)$ and left-right delay in myocardial shortening (47). 
ECG-gated SSFP cine images can quantify RV chamber size and systolic function (18). RV cardiac output can be estimated by multiplying the determined RV stroke volume (SV) by the heart rate during the image acquisition of the cine stacks. Axial views of the heart chambers reveal a change in $R V$ morphology from its usual crescent shape to a more rounded contour due to concentric hypertrophy, as well as RV dilation. Other abnormalities that can be seen with $\mathrm{PH}$ include RV hypertrophy, reduced RVEF, RV wall motion abnormalities, septal abnormalities, TR, and RA enlargement (Figure 5) (48). In individuals with $\mathrm{mPAP} \geq 30 \mathrm{mmHg}$, a systolic leftward deviation of the IVS had $86 \%$ sensitivity and $91 \%$ specificity for detecting $\mathrm{PH}$ (49). Finally, RV mass is greater in PH compared to healthy controls; a ventricular mass index (RV mass divided by $\mathrm{LV}$ mass) $>0.6$ is suggestive of $\mathrm{PH}$ (sensitivity $84 \%$ and specificity $71 \%)(40)$.

DE-CMR (Figure 6) can identify areas of prolonged retention (i.e., delayed clearance) of GBCA from the extracellular space, which becomes increased in areas of fibrosis and scar. This can be seen as DE at the RV septal insertion sites near the base of the heart $(50,51)$, a frequent finding in $\mathrm{PH} .>80 \%$ of patients with $\mathrm{PH}$ have some amount of $\mathrm{DE}$, with almost $30 \%$ having $\mathrm{DE}$ involving the RV insertion points and extending to the midmyocardial wall of the IVS (52). The dynamic changes that occur in the motion of the IVS secondary to increased mechanical stress in the setting of chronically high RV pressures are hypothesized to cause fibrosis and abnormal $\mathrm{DE}$ at these insertion points $(53,54)$ and correlates with lower RVEF. PH-associated DE is correlated to increased main pulmonary artery (MPA) pressures, RV hypertrophy, and RV dilation (55), in particular DE involving the IVS is more strongly associated with other parameters of RV failure (52).

\section{$\mathrm{PC}$ and Cine Imaging Techniques in Relation to RH-PA Flow and Hemodynamics}

PC-CMR permits the assessment of shunts, forward and regurgitant flow, RVSV, and PA velocity $(45,56)$, as well as advanced visualization of flow patterns to evaluate PA distensibility, coronary flow reserve, wall shear stress (WSS), and turbulence (57). PC velocity mapping is a sequence that is used to measure velocity and blood flow in vessels. PA blood flow can be measured using 2D PC flow sequences (58). This quantifies flow based on magnetic field gradients inducing phase shifts in moving protons that are proportional to their velocity and the strength of the velocity encoding (VEnc) gradient that is used. PC-CMR can be prescribed such that it detects the flow either throughplane or in-plane with respect to the plane of image acquisition. For quantitative 2D PC-CMR, image acquisition is prescribed via the through-plane mode, with the most accurate quantification obtained when the imaging plane is orthogonal to the vessel of interest. Peak PASP can be derived using the modified Bernoulli equation and identifying the peak TR velocity via $2 \mathrm{D}$ PC-CMR at the level of the TV, analogous to the method use in Doppler TTE.

In the setting of $\mathrm{PH}$, quantifying cardiac shunts with the pulmonary-to-systemic flow ratio (Qp:Qs) by performing PCCMR at the MPA and ascending aorta (AAo) (40). RVSV can be calculated by performing volumetric analysis (RV end-diastolic
volume-RV end-systolic volume) or by using PC imaging to measure flow in the MPA (Figure 7). In the presence of considerable TR, RVSV calculated by MPA flow is more reliable than volumetric analysis because the latter often overestimates the true systolic volume (59). Another important parameter that can be evaluated with PC imaging is the average flow velocity in the MPA. Investigators have reported a decrease in the average MPA velocity in patients with $\mathrm{PH}$; mean average velocity in MPA was $<11.7 \mathrm{~cm} / \mathrm{s}$, with $93 \%$ sensitivity and $82 \%$ specificity for detecting $\mathrm{PH}$ when compared to RHC-derived measurements of PA pressures and resistance (60).

Distensibility is defined as the relative change in crosssectional area (CSA) of the MPA throughout the cardiac cycle multiplied by the pulse pressure required to induce that change. Since the MPA pulse pressure is not readily known, the pulsatility or relative area change (RAC) is used as a surrogate marker of MPA stiffness (61), where RAC is calculated as:

$$
\frac{\text { maximum MPA CSA - minimum MPA CSA }}{\text { maximum MPA CSA }}
$$

MPA RAC can be combined with RHC data to calculate additional indices of proximal PA stiffness, including compliance, distensibility, elastic modulus, and stiffness index $(61,62)$, for which virtually all types of $\mathrm{PH}$ result in proximal PA stiffening and contribute to progressive decline in RV function.

PC-CMR can also evaluate coronary perfusion of the RV and detect RV ischemia, which leads to RV failure in PH (18). One study of PAH patients found that right coronary artery (RCA) peak and mean systolic flow was significantly decreased compared to control patients; these changes were inversely correlated to RV mass and RV pressure (63). Finally, PCCMR has also been used to determine advanced hemodynamic parameters such as pulse-wave velocity, vorticity, and WSS (18). With newer, faster scanners, PC-CMR has evolved into more sophisticated acquisitions, including time-resolved, 3D, and fourdimensional (4D) flow magnetic resonance imaging (MRI) (64).

Proximal PA changes are common in PH. Pulse-wave velocity, the rate at which the systolic wave propagates through the vessels, in the central PAs is an imaging correlate regarding MPA stiffness $(65,66)$. Due to the short length of the MPA and low temporal resolution of MRI, the MPA pulse-wave velocity is typically estimated using the flow-area method $(65,67)$. 4D flow MRI has been used to assess the hemodynamic changes in the pulmonary circulation in the setting of $\mathrm{PH}$, which can non-invasively measure complex 3D hemodynamic changes with full volumetric coverage of the RV and PA (48). There can be development of abnormal vortices in the MPA in PH $(68,69)$. Another parameter characterized with $4 \mathrm{D}$ flow is MPA WSS, which affects smooth muscle tone through mechanical transduction and has impact on vascular remodeling (70-72). Comparing $\mathrm{PH}$ patients with healthy controls, WSS was significantly lower $(p$ $<0.05)$ in those with PH (73). 4D flow MRI has demonstrated low interobserver variability, high reproducibility, and good correlation between flow parameters obtained with 4D flow and 2D-cine PC-CMR $(74,75)$.

As PASP increases, RVSP can be rise above LV systolic pressure, impeding LV function because of shifting of the IVS 


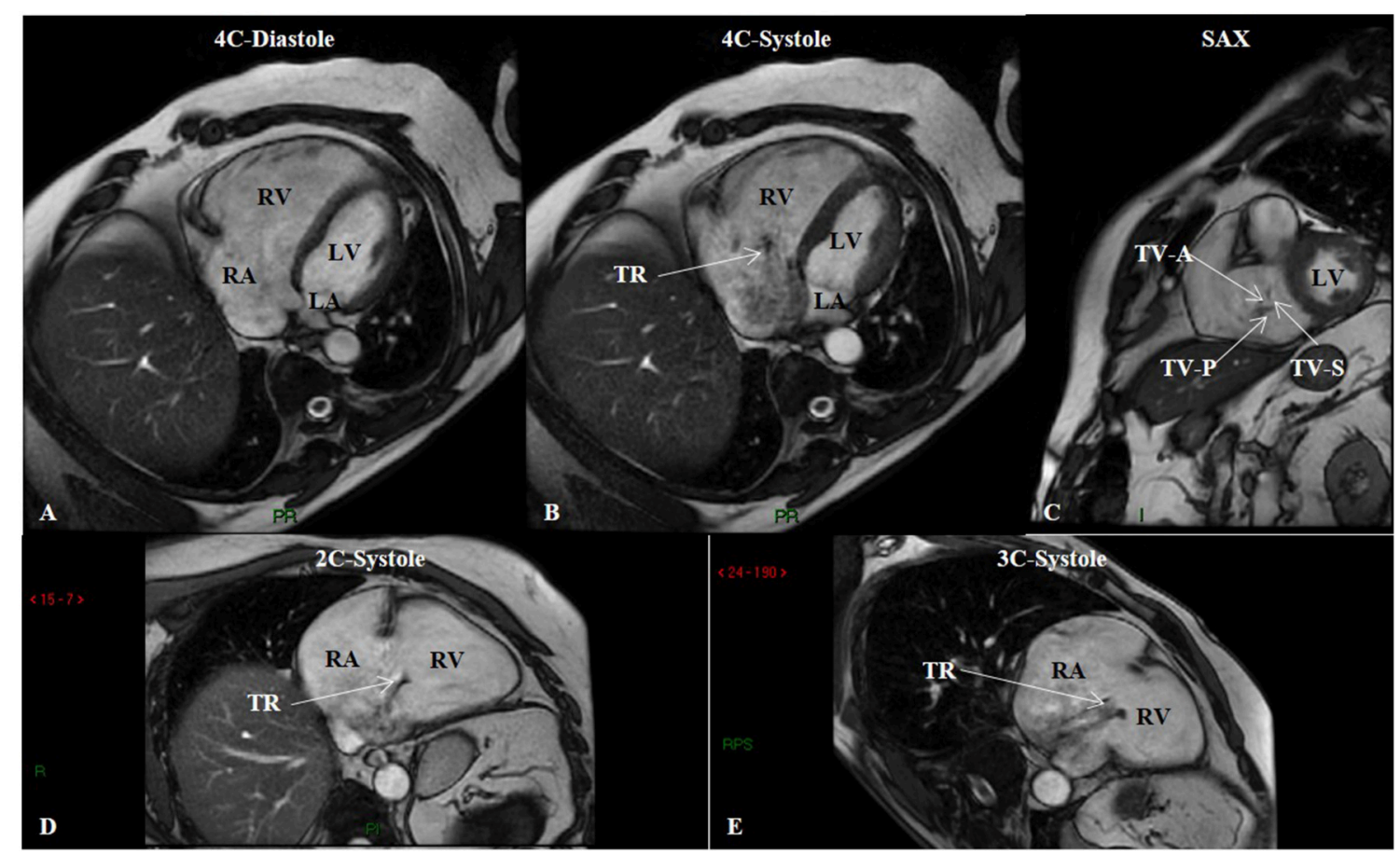

FIGURE 5 | Steady-state free precession (SSFP) cine imaging by cardiac magnetic resonance of a patient with group 3 pulmonary hypertension. SSFP in the four-chamber (4C) orientation at end-diastole (A) showing right ventricular enlargement, and at mid-systole (B) showing tricuspid regurgitation. (C) SSFP in the short-axis (SAX) orientation depicts malcoaptation of the tricuspid valve leaflets. SSFP in the two-chamber (2C) (D) and three-chamber (3C) (E) orientations in systole showing again tricuspid regurgitation. LA, left atrium; LV, left ventricle; RA, right atrium; RV, right ventricle; TR, tricuspid regurgitation; TV-A, tricuspid valve anterior leaflet; TV-P, tricuspid valve posterior leaflet; TV-S, tricuspid valve septal leaflet.
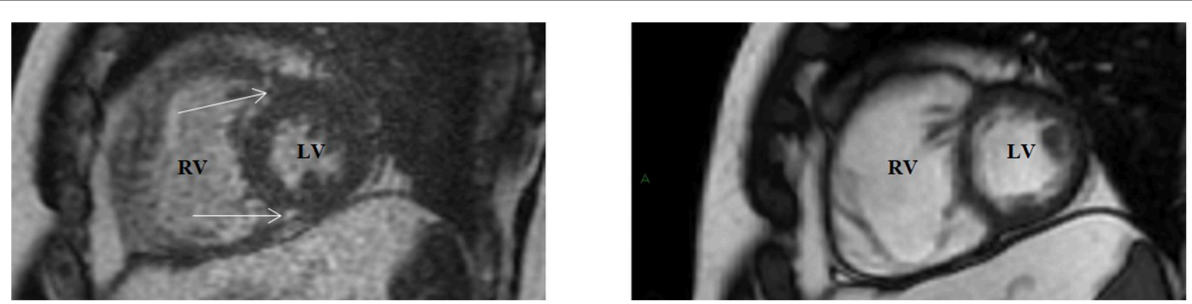

FIGURE 6 | Delayed enhancement (DE) cardiac magnetic resonance in the short-axis view (Left) showing gadolinium hyperenhancement at the right ventricular septal insertion points (arrows), with corresponding slice on cine imaging (Right) showing right ventricular enlargement. LV, left ventricle; RV, right ventricle.

into the LV outflow tract (76) and ventricular dyssynchrony between RV and LV $(47,77)$. Severe and prolonged PH can even lead to RV diastolic dysfunction, resulting in flattening or bowing of the IVS during diastole and impaired LV filling. IVS motion abnormalities such as flattening or leftward bowing of the IVS during diastole (due to chronic volume overload) and/or systole (due to chronic pressure overload) can be identified and suggest $\mathrm{PH}$ by correlating to elevated $\mathrm{RH}$ pressures. Septal bowing is indicative of PASP $\geq 67 \mathrm{mmHg}$, leading to impaired filling in early diastole and associated LV abnormalities of reduced LV end-diastolic volume and decreased $\operatorname{LVSV}(48,49)$. Studies have reported varying positive correlations between ventricular mass index and mPAP (range 0.56-0.81) (40). CMR may also be employed to evaluate LV/RV interdependence and coupling (78).

\section{Cardiovascular Computed Tomography}

Advantages of CT include ability to obtain images that require little scan time, excellent spatial and temporal resolution, and capability to comprehensively evaluate the cardiopulmonary structures. While CT plays less of a first-line role in the diagnosis of $\mathrm{PH}$, the modality can have major impact on investigating the underlying cause of the $\mathrm{PH}$, as it can visualize lung parenchyma, vasculature, and the heart. It can also assess $\mathrm{CV}$ changes secondary to $\mathrm{PH}$, allowing for evaluation of disease severity. Different types of modern-day multidetector CT (MDCT) scans include non-contrast high-resolution CT (HRCT) and contrastenhanced CT angiography (CTA) (26). The technology has moved beyond single-source 4-, 16-, and 64-slice CT scanners, and currently scanners with more detector rows (up to 128-, 

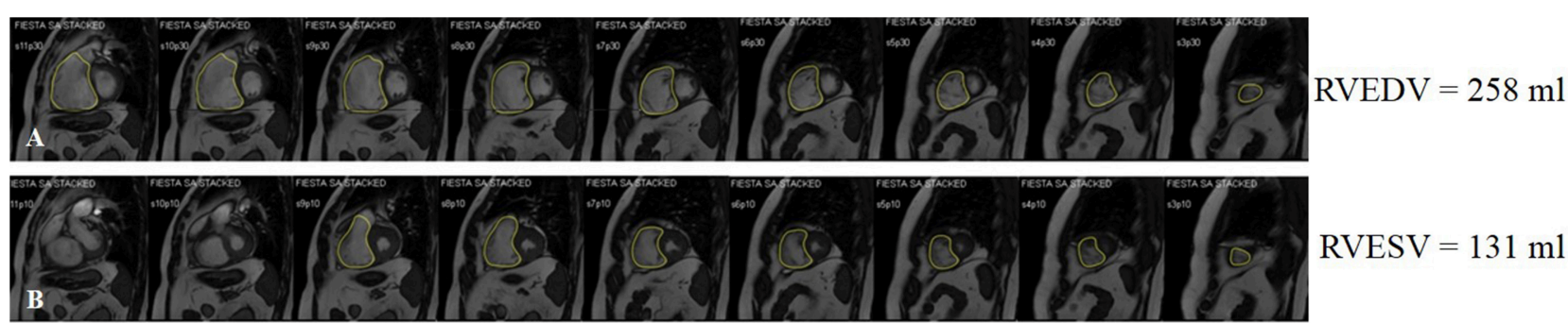

$\operatorname{RVESV}=131 \mathrm{ml}$

$$
\begin{aligned}
& \mathrm{RVSV}=258-131 \mathrm{ml}=127 \mathrm{ml} \\
& \mathrm{RVEF}=127 \mathrm{ml} / 258 \mathrm{ml}=49 \%
\end{aligned}
$$
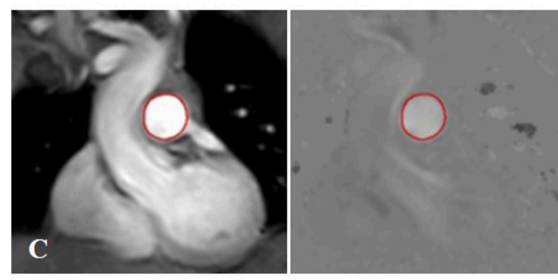

$\mathrm{PA} \mathrm{Vol}=69 \mathrm{ml}$

TR Vol $=127 \mathrm{ml}-69 \mathrm{ml}=58 \mathrm{ml}$ TR Frac $=58 \mathrm{ml} / 125 \mathrm{ml}=46 \%$

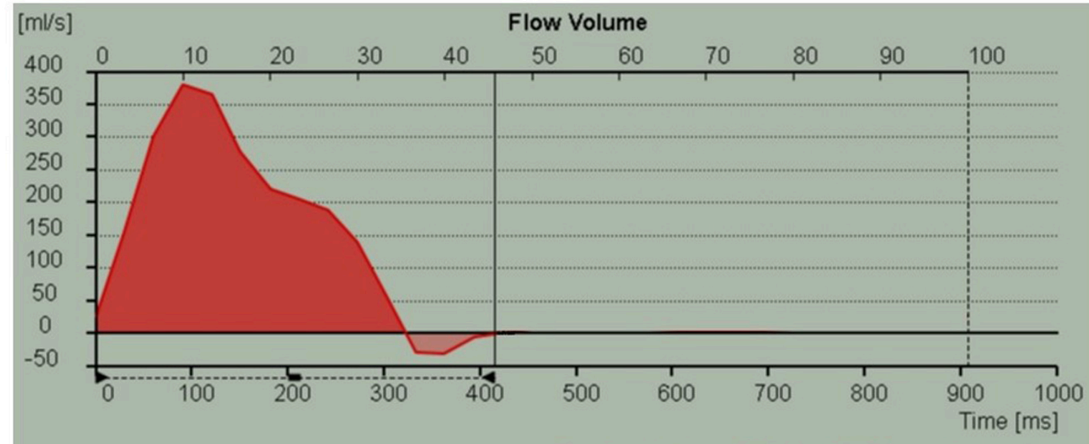

D
Forward flow volume: $69.16 \mathrm{ml} 4.57 \mathrm{Vmin}$ Backward flow volume: $1.73 \mathrm{ml} \quad 113.99 \mathrm{ml} / \mathrm{min}$ Regurgitant fraction: $2 \%$

FIGURE 7 | Cardiac magnetic resonance volumetric and flow analysis of a patient with group 3 pulmonary hypertension. (A) Steady-state free precession cine imaging stack in the short-axis view displayed from base (left) to apex (right) at end-diastole (A) and end-systole (B). The endocardium of the right ventricle has been traced (yellow contours) with signs of septal straightening and change from a crescent contour to a more rounded contour. The slice contours have been summated, showing right ventricular end-diastolic and end-systolic volumes, and the calculated right ventricular ejection fraction. (C) Phase-contrast (PC) imaging performed through the proximal pulmonary artery (red contours) with magnitude- (left) and phase- (right) encoded images in corresponding spatial orientation. (D) Flow-time curve showing the volume detected in the pulmonary artery. Indirect determination of tricuspid regurgitation volume involving subtraction of the pulmonary artery flow volume derived from PC imaging from the calculated right ventricular stroke volume, as well as the tricuspid regurgitant fraction. Frac, fraction; PA, pulmonary artery; RVEDV, right ventricular end-diastolic volume; RVEF, right ventricular ejection fraction; RVESV, right ventricular end-systolic volume; RVSV, right ventricular stroke volume; TR, tricuspid regurgitation; Vol, volume.

256-, and 320-slice) and dual-source (DSCT) are becoming more widely used, which have improved the modality's spatial and temporal resolution (79). If the patient referred for CT already has a known diagnosis of PH, a non-ECG-gated non-contrast and contrast-enhanced CT can be performed for the evaluation of the $\mathrm{PA}$ and lung parenchyma. If there is a concern for PE and detailed assessment of CV structures is desired, an ECG-gated CTA can be performed.

\section{Non-contrast CT Techniques Regarding Non-cardiac Structures}

CT is indicated for the evaluation of the lungs in patients with chronic unexplained shortness of breath (20). A brief review follows regarding the utility of non-CV findings. Noncontrast and HRCT is used to assess the extent and severity of diffuse, interstitial lung disease (80) and chronic obstructive pulmonary disease (COPD) (81-83). It can also help in identifying pulmonary arteriovenous malformations (AVMs), pulmonary veno-occlusive disease (PVOD), and pulmonary capillary hemangiomatosis (PCH) (84).

Historically, the Framingham Heart Study (FHS) provided the largest cohort $(n=706)$ used to define normal PA size reference ranges (85). Investigators reviewed non-contrast chest CTs of this "healthy" cohort (non-smokers without obesity, hypertension, diabetes, CV disease, COPD, history of pulmonary embolism (PE), or heart valve surgery). The mean \pm standard deviation (SD) main PA (MPA) diameter was $25.1 \pm 2.8 \mathrm{~mm}$, and the sex-specific 90th percentile cutoff value for MPA diameter was $28.9 \mathrm{~mm}$ in men and $26.9 \mathrm{~mm}$ in women. The diameter of the MPA was associated with increased risk for self-reported dyspnea (adjusted odds ratio 1.31, $p=0.02$ ).

\section{Contrast-Enhanced CTA Techniques Regarding Vasculature}

CTA requires the IV administration of iodinated contrast agent to visualize the PA, and today has become the widely accepted modality of choice to diagnose acute PE, given its ability to now routinely evaluate main, lobar, segmental, and subsegmental PAs (86). However, while CTA has replaced $\mathrm{V} / \mathrm{Q}$ in detecting acute PE, CTA's role in CTEPH is less well established (87) relative to V/Q when comparing to conventional pulmonary angiography. Nevertheless, a novel high-pitch ECGsynchronized computed tomographic pulmonary angiography (CTPA) protocol has been developed to allow for better contrast 
opacification of the PA at reduced radiation dose (88), making CTPA an increasingly more attractive option. Dilatation of the main, right, and left PAs is the most conspicuous finding on CT. Other findings of PH include calcification, tortuosity, and rapid tapering of the PAs. Persistently high PA pressures cause vascular remodeling, resulting in PA wall thickening and dilation (10). However, the differential diagnosis for a dilated PA on CTPA is broad. Etiologies include PH and its various causes, increased or turbulent blood flow (for example, left-to-right shunt: patent ductus arteriosus, atrial or ventricular septal defect), rheumatologic diseases (Behçet disease, Takayasu arteritis), connective tissue diseases (Marfan syndrome, Ehlers-Danlos syndrome, cystic medial necrosis), infections (tuberculosis, syphilis), trauma, or idiopathic (10). Caution should be used when using MPA dilatation as a criterion for PH in patients with pulmonary fibrosis, because MPA dilatation can occur in the absence of $\mathrm{PH}$ in patients with chronic pulmonary disease (89).

Besides FHS, other studies of normative reference ranges for PA size have been varied, given differences in demographics, medical comorbidities, ECG-gated examinations, use of IV contrast, window settings, and measuring methodology (the entire vessel diameter versus the vascular lumen) (10). On CTPA transverse images with the contrast ideally timed for opacification of the PAs, the MPA is evaluated at the level of its bifurcation, orthogonal to its long axis, and general consensus in the literature has been that a MPA diameter of at least $29 \mathrm{~mm}$ is potentially compatible with $\mathrm{PH}(24,40)$, with the caveat that sensitivity and specificity for detecting $\mathrm{PH}$ vary based on the type of $\mathrm{PH}$ and $\mathrm{PA}$ diameter cutoff used. In an older study, MPA diameter $\geq 29 \mathrm{~mm}$ had a $97 \%$ positive predictive value, $89 \%$ specificity, and $87 \%$ sensitivity for the presence of PH (90). A systematic review of the sensitivity and specificity of different PA diameter cutoffs for identifying $\mathrm{PH}$ found an average reported cutoff of $29.5 \mathrm{~mm}$ (range 25.0-33.2) among 12 studies that included patients from different $\mathrm{PH}$ groups (10). Average sensitivity and specificity for detecting $\mathrm{PH}$ was $72 \%$ (range $47-87 \%$ ) and $81 \%$ (range $41-$ $100 \%$ ), respectively. However, a diameter of $<29 \mathrm{~mm}$ does not definitively exclude PH. In those with mild PH, the PA may only be slightly or borderline dilated, and findings in patients with $\mathrm{PH}$ can overlap with those in control subjects without $\mathrm{PH}(90,91)$. In a study with subjects with mPAP $>25 \mathrm{mmHg}$ versus controls with mPAP $<25 \mathrm{mmHg}$, it was concluded that mean MPA diameter in patients without $\mathrm{PH}$ is $27.5 \pm 0.5 \mathrm{~mm}$ in men and is $25.7 \pm$ $0.4 \mathrm{~mm}$ in women, with a threshold of $29.0 \mathrm{~mm}$ having a $52 \%$ sensitivity and a $90 \%$ specificity for the prediction of mPAP $>25$ $\mathrm{mmHg}$ (92). The diameters of segmental PAs should also be equal to those of adjacent bronchi. In the presence of a dilated MPA $(\geq 29 \mathrm{~mm}$ ), a segmental artery-to-bronchus diameter ratio of 1:1 or more in at least 3 lobes has a specificity of $100 \%$ for the presence of $\mathrm{PH}(90)$.

Several studies have suggested a strong association between the diameter ratio of MPA to ascending aorta (AAo) and PA pressure (in the absence of ectasia or ascending aortic aneurysm) (92, 93); an MPA to AAo diameter ratio greater than 1.0 was $70.8 \%$ sensitive and $76.5 \%$ specific in predicting $\mathrm{mPAP}>25$ $\mathrm{mmHg}$ (92). FHS found that the normal mean \pm SD ratio of MPA to AAo diameter was $0.77 \pm 0.09$, with a 90th percentile cutoff value for MPA:AAo ratio of 0.9 in both men and women (85). The MPA:AAo diameter ratio appears to be a stronger predictor of mPAP than MPA diameter alone or MPA diameter indexed to body surface area (BSA) (94). In those younger than 50 years of age, a MPA transverse diameter larger than that of the AAo on CTPA is also a sign of $\mathrm{PH}$, with $96 \%$ positive predictive value and $92 \%$ specificity (95). MPA:AAo diameter ratio significantly correlated with RHC-derived mPAP $\left(r^{2}=0.45, p<0.001\right)$; a composite index that utilizes (1) the MPA:AAo size ratio and (2) echo-derived RVSP incrementally enhanced PH detection (specificity 96\%) when compared to using each modality alone (96). However, the confounding issue with incorporating aortic measurements in the diagnosis of $\mathrm{PH}$ by $\mathrm{CT}$ is that diseases unrelated to $\mathrm{PH}$ can cause dilatation of the AAo. The tradeoff was reduced sensitivity (59\%), thus clinicians should be mindful that clinically significant disease may still be present despite a normal MPA:AAo size ratio in the setting of a concurrently dilated aorta.

As determined by ECG-gated CTPA for visualizing signs of $\mathrm{PH}$, right PA distensibility (defined as the percentage change in CSA between diastole and systole, calculated by:

$$
\frac{\text { maximum CSA }- \text { minimum CSA }}{\text { maximum CSA }} \times 100
$$

was reported to be an accurate non-invasive marker for $\mathrm{PH}$, with reduced right PA distensibility having the strongest correlation to mPAP (97). The threshold for distinguishing between patients with and without PH was a distensibility of $16.5 \%$ (sensitivity $86 \%$ and specificity $96 \%$ ).

Finally, anatomic manifestations of a profoundly dilated PA sometimes need to be considered, due to compression of critical mediastinal structures. Recognition of the compression of anatomic structures due to PH sequelae is crucial as early diagnosis and aggressive treatment is critical. Elevated PA pressure and PA size may result in extrinsic compression of the left main coronary artery and subsequent LV myocardial ischemia $(98,99)$. MPA diameter $>4 \mathrm{~cm}$ and a MPA:AAo diameter ratio $>1.21$ pose higher risk of left main coronary artery compression and subsequent complications (100). While CTPA can suggest this diagnosis, ideally coronary angiography with intravascular ultrasound is needed for confirmation $(98,101)$. An enlarged PA can compress the left recurrent laryngeal nerve, resulting in cardiovocal (Ortner's) syndrome, characterized by vocal cord palsy and hoarseness. CT or MR of the head and neck may aid in identifying the site of the nerve compression, but definitive diagnosis requires laryngoscopy. Finally, a dilated PA can compress the tracheobronchial tree; the most common site of compression is where the left PA crosses the superior aspect of the left main bronchus (99).

\section{Multislice CT Techniques Regarding Cardiac Findings} ECG gating improves evaluation of RV adaptive changes and signs of RH failure, including chamber enlargement and wall thickness hypertrophy (102). Older studies from the 1990s and 2000s correlated PH and RH dysfunction with RV hypertrophy (defined as wall thickness $>4 \mathrm{~mm}$ ), straightening or leftward bowing of the IVS, RV dilatation (defined RV:LV diameter ratio 
at the mid-ventricular level on axial images $>1: 1$ ), RV systolic dysfunction, suggestion of TR (demonstrated by contrast reflux into the IVC and hepatic veins), dilation of IVC and hepatic veins, and/or pericardial effusion (Figure 8) (103-106). A more recent study showed that increased $(\geq 6 \mathrm{~mm})$ RV free wall enddiastolic thickness, increased RV:LV chamber lumen ratio $\geq 1.28$, and RV:LV wall ratio $\geq 0.32$ also predicted $\mathrm{PH}$ (107).

\section{Radionuclide Scintigraphy}

Historically, prior to advent of echocardiography, radionuclide imaging was the first non-invasive modality used to obtain accurate and reproducible measurements of the RV (108). But as previously mentioned, the complex morphology of the RV with its relatively thinner wall and coarse trabeculations, as well as lack of a simple geometrical model to define its shape, has made the assessment of RV structure and function difficult. Nevertheless, strides have been made in radionuclide scintigraphy, and the RV has been assessed with the modality in certain subsets of PH. Although nuclear cardiology evaluation of the RV still suffers from several technical limitations, it can characterize systolic function, perfusion, and metabolism, providing diagnostic and prognostic information that can be integrated with data from other non-invasive imaging. Since nuclear imaging with the application of newer techniques can assess RV perfusion and metabolism in addition to morphology and EF, the modality can provide opportunities for a comprehensive RV evaluation from a single study.

\section{Molecular Imaging: RV Oxygen Consumption and Perfusion/Blood Flow}

With a combination of ${ }^{15} \mathrm{O}$-labeled tracers $\left({ }^{15} \mathrm{O}-\mathrm{H}_{2} \mathrm{O},{ }^{15} \mathrm{O}\right.$ $\mathrm{CO}$, and $\left.{ }^{15} \mathrm{O}-\mathrm{O}_{2}\right)$ or with ${ }^{11} \mathrm{C}$-acetate tracers, positron emission tomography (PET) imaging allows for estimation of RV myocardial oxygen consumption $(109,110)$. For example, resting myocardial oxygen consumption is significantly elevated in individuals with PAH (111); with progression of $\mathrm{PAH}$, the efficiency of the RV increasingly decreases.

\section{APPLICATION OF IMAGING FOR ELUCIDATION OF SUBSETS OF PH: DIAGNOSTIC EVALUATION BY CLASSIFICATION OF THE PH PATIENT}

Initial evaluation of a patient with suspected pulmonary hypertension usually begins with an echocardiogram; however, to help define the etiology further imaging modalities are required. It is important to identify certain groups of $\mathrm{PH}$ for which there are specific therapies. For example, certain vasoactive substances for group $1 \mathrm{PAH}$ and pulmonary embolectomy for group 4 $\mathrm{CTEPH}$. Also, elucidation of group 2 or $3 \mathrm{PH}$ is beneficial in order to treat the underlying left heart or pulmonary causes.

\section{Group 1 PH}

Pulmonary arterial hypertension is usually a diagnosis of exclusion. There is not one particular imaging modality that characteristically defines PAH. In one study, left atrial volume as determined by CMR was demonstrated as having sufficient ability to distinguish idiopathic PAH from $\mathrm{PH}$ due to heart failure with preserved EF with $97 \%$ sensitivity and 100\% specificity (112). In another study, early onset of retrograde flow in the MPA detected by standard PC-CMR quantification was characteristic of PAH (113).

Increased MPA and RV diameters and increased MPA:AAo and RV:LV ratios are correlated with increased pulmonary vascular resistance in patients with $\mathrm{PAH}$ in the setting of systemic sclerosis (114). However, these CT-based metrics are less predictive of PAH severity than MR imaging and echobased measurements (115). Pulmonary AVMs in hereditary hemorrhagic telangiectasia (group 1.2.2) can be accurately detected with CT, appearing as a nodular opacity with a feeding artery and a draining vein $(116,117)$. While in most patients with hereditary hemorrhagic telangiectasia noncontrast CT is sufficient to identify pulmonary AVMs, CTA can be employed when characterizing larger pulmonary AVMs (118). CT findings in PVOD and PCH (group 1') reflect the underlying hemodynamic changes. With Group $1 \mathrm{PH}$, the vascular pattern on CTPA can show rapid tapering of the peripheral PAs and "corkscrew" appearance of the vessels (119). Typically with idiopathic $\mathrm{PAH}$, there is symmetric enlargement of the PA.

\section{Group 2 PH}

LV filling pressure is an important factor for defining group $2 \mathrm{PH}$ due to $\mathrm{LH}$ disease, and this distinguishes it from group $1 \mathrm{PAH}$, in which there is no concurrent increase in LV filling pressure (120). Though echocardiography is probably the main imaging modality used in this group of patients with its ability to assess filling pressures, CMR aids in further identification, characterization, and understanding of the severity of valve or congenital heart disease. Shunts and aberrant pulmonary veins that are not easily found on echocardiography may be better seen on CMR using MRA imaging. If the echo findings are inconclusive for group $2 \mathrm{PH}$, CMR may be used to determine presence of CHD (26) or $\mathrm{LH}$ disease (121).

By CT, patients with $\mathrm{PH}$ secondary to $\mathrm{LH}$ disease have larger MPA diameters (severe $\mathrm{PH}, 38.3 \pm 0.9 \mathrm{~mm}$; mild to moderate $\mathrm{PH}, 34.9 \pm 1.0 \mathrm{~mm})$ than those without $\mathrm{PH}(27.4 \pm 0.9 \mathrm{~mm})$ (122). In addition, CTA-derived size ratio of the left to right atrium can distinguish between $\mathrm{PH}$ due to heart failure with preserved ejection fraction and idiopathic PAH (123). LA/RA ratio was significantly larger in those with preserved ejection fraction than idiopathic PAH $(p<0.001)$. Mean LA size was 27 $\pm 6 \mathrm{~cm}^{2}$ (transaxial view without reconstruction) and $29 \pm 7$ $\mathrm{cm}^{2}$ (after multiplanar 4-chamber view reconstruction) in those with preserved ejection fraction, compared to $19 \pm 5 \mathrm{~cm}^{2}$ and 21 $\pm 5 \mathrm{~cm}^{2}$ for the respective views in those with idiopathic $\mathrm{PAH}$ $(p<0.001)$; RA size was not different between groups. The use of a size ratio provides the advantage of intrinsically accounting for patient size, and in this particular study it was demonstrated that the ratio remained unaffected by the temporal point in the cardiac cycle. 


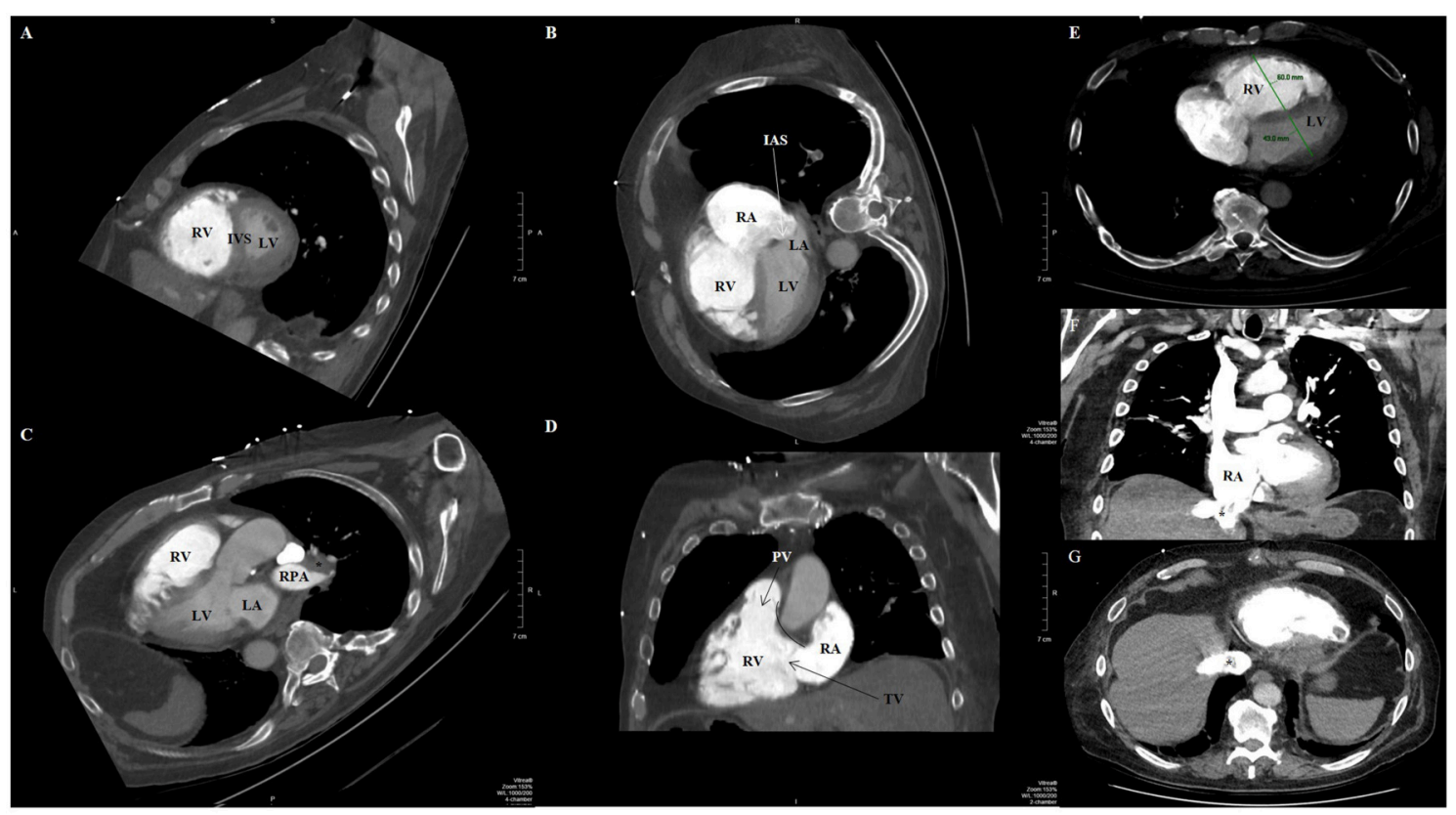

FIGURE 8 | Contrast-enhanced computed tomography timed for the right heart and pulmonary artery circulation of a patient with pulmonary hypertension and pulmonary embolism, reformatted into cardiac views (A-D). (A) Short-axis view at the level of the ventricles reveals right ventricular dilation and interventricular septal flattening and bowing toward the left ventricle. (B) Four-chamber view showing both right ventricular and right atrial dilatation, and bowing of the interatrial septum. (C) Three-chamber view showing again enlarged right ventricle, as well as filling defect (asterisk) compatible with pulmonary embolism in the right pulmonary artery. (D) Two-chamber view dedicated to the right heart showing the right ventricular inflow and outflow, where the tricuspid and pulmonic valves can be seen, including the discontinuity between the atrioventricular (tricuspid) and semilunar (pulmonic) valves that characterizes the morphologic right ventricle. (E) Transaxial view showing increased RV:LV diameter ratio (1.4). Coronal (F) and transaxial (G) views showing contrast reflux (asterisks) into the inferior vena cava and hepatic venous system compatible with significant tricuspid regurgitation. IAS, interatrial septum; IVS, interventricular septum; LA, left atrium; LV, left ventricle; PV, pulmonic valve; RA, right atrium; RPA, right pulmonary artery; RV, right ventricle; TV, tricuspid valve.

\section{Group 3 PH}

Both non-contrast and contrast CT can accurately characterize group $3 \mathrm{PH}$. CT characterizes the type of emphysema, the presence of airway disease, and secondary features associated with smoking-related pulmonary disease (81-83, 124, 125). Recently developed quantitative CT methods of assessing emphysema severity correlate with histologic $(126,127)$ and clinical (128-130) parameters. Patients with PH secondary to lung disease have both increased MPA diameter and increased MPA:AAo ratio, with $>1: 1$ being most strongly correlated with increased PASP in multivariate analysis (131).

\section{Group 4 PH}

Though echocardiography may delineate effects of elevated right-sided pressures in patients post-PE with right ventricular hypertrophy and systolic dysfunction, and dilatation of the right chambers, evidence of vascular consequences in the evaluation of CTEPH (group 4) is gained by a ventilation/perfusion (V/Q) scan (Figure 9). CTEPH occurs eventually in up to approximately $4 \%$ of patients following an initial acute PE (132), and is more common in patients with multiple thromboembolic events (133). V/Q scanning has high sensitivity (>96\%) and specificity (>90\%) $(87,134)$ when interpreted using the modified Prospective Investigation of Pulmonary Embolism Diagnosis (PIOPED) criteria. V/Q is most useful as a screening study for CTEPH, which can be essentially excluded with a sensitivity (90-100\%) and specificity (94-100\%) approaching unity if the V/Q scan is normal or of low probability (135), compared to a sensitivity of 50-98\% with similar specificity via CTPA (87). V/Q scan also has a higher sensitivity compared to CTPA in detecting distal areas of disease (136).

Patients with CTEPH show wedge-shaped perfusion defects with normal ventilation on V/Q scan. However, complete lack of perfusion to a lung may indicate other conditions such as malignancy, vasculitis, or fibrosing mediastinitis (136). Unmatched perfusion defects can be seen in other pulmonary vascular diseases like group 1' (PVOD and $\mathrm{PCH}$ ), which is relevant because such patients with these conditions can develop pulmonary edema if treated with pulmonary vasodilator agents (137).

V/Q scans do not require iodinated contrast and have less radiation exposure than CTPA; the estimated effective dose for V/Q scan is $0.6-3$ milliSieverts $(\mathrm{mSv})$, whereas for 16-row or greater multidetector CT, it is $8-20 \mathrm{mSv}$ (138). Several limitations of this imaging modality include the risk of non-diagnostic or indeterminate scans, underestimation of the extent of central vascular obstruction, and the challenge of differentiating between similarly presenting pulmonary diseases such as PVOD or fibrosing mediastinitis, resulting in increased downstream evaluation with cross-sectional imaging to confirm 

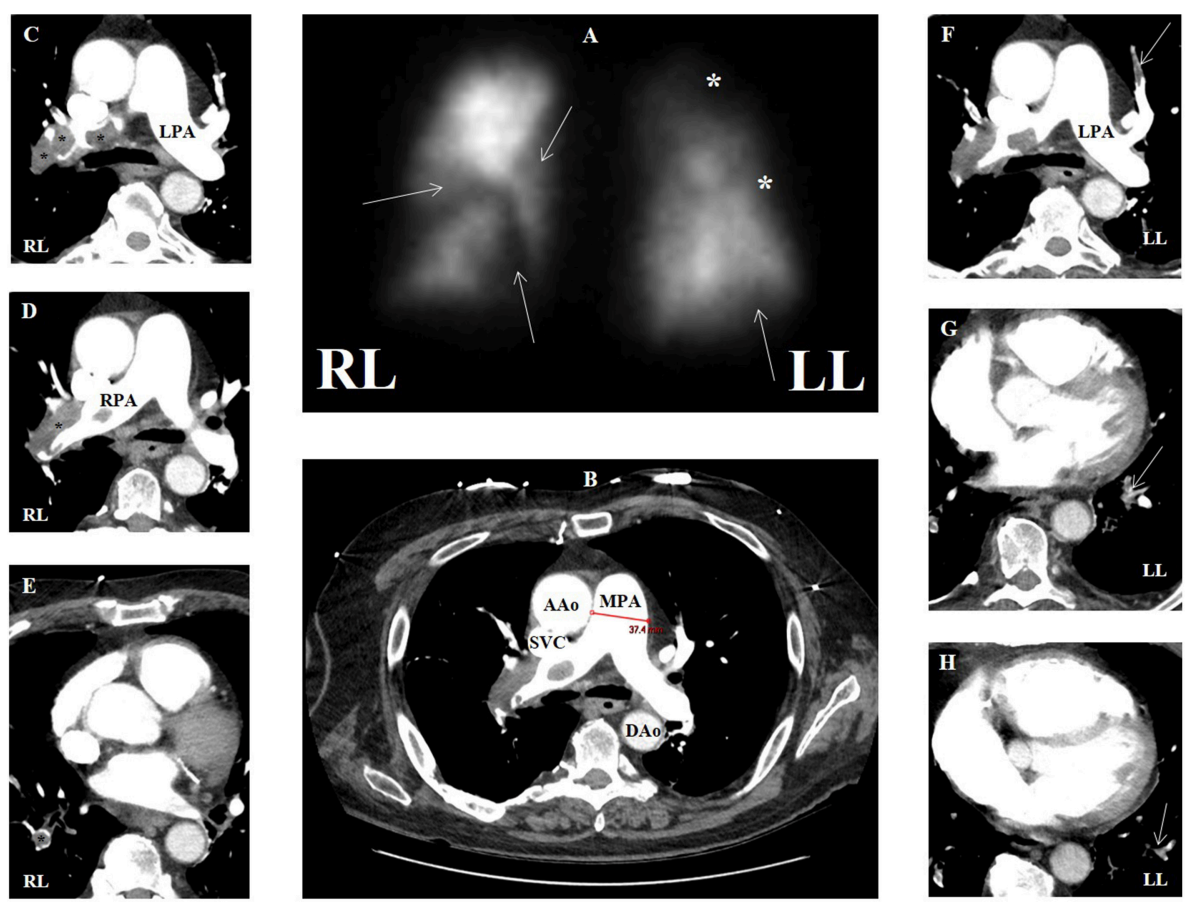

FIGURE 9 | (A) Ventilation-perfusion scan in a patient with group 4 pulmonary hypertension with multiple segmental defects (arrows) and additional areas of possible defect (asterisks), overall with high probability for pulmonary embolism. (B) Contrasted computed tomographic angiography (CTA) in transaxial view of same patient showing main pulmonary artery dilation $(3.7 \mathrm{~cm}$ ) compatible with pulmonary hypertension. (C-E) CTA showing multiple areas of filling defect consistent with pulmonary emboli (asterisks) that correspond to perfusion defects in the right lung. (F-H) CTA showing multiple areas of filling defect compatible with pulmonary emboli (arrows) that may correspond to perfusion defects in the left lung. AAo, ascending aorta; DAo, descending aorta; LL, left lung; LPA, left pulmonary artery; MPA, main pulmonary artery; RL, right lung; RPA, right pulmonary artery; SVC, superior vena cava.

vascular and lung findings and to provide further information of the anatomic extent of disease $(139,140)$.

Group 4 CT abnormalities compatible with CTEPH are present in approximately $90 \%$ of such patients; these include RV hypertrophy, IVS straightening, complete PA luminal obstruction, intimal irregularities, pouch-like defects, bands, webs, mural thrombus, enlargement of bronchial arteries due to collateral blood supply, and mosaic lung attenuation $(141,142)$. With CTEPH, the vascular pattern on CTA can show more irregular PA dilation with thrombi, which may appear calcified. MPA diameter, RV:LV diameter ratio, and RV wall thickness have been found to correlate with MPAP in CTEPH (143). Although the Qanadli (144) and Mastora (145) indices have been developed to quantify the overall obstructive burden of chronic PE in these patients, these CTA parameters of PA obstruction do not correlate with RV function or pulmonary vascular resistance indices $(143,146)$.

Contrasted MRA of the PA showing filling defects might suggest group 4 (CTEPH) (121). Newer, dynamic contrastenhanced (DCE) MRA is highly sensitive and specific for the diagnosis of CTEPH (147).

\section{PROGNOSTICATION}

Beyond baseline diagnosis, the various modalities offer potential prognostic information. While CXR has limited prognostic utility, chronic pericardial effusion associated with advanced $\mathrm{PH}$ can be seen on CXR as an enlarged cardiac silhouette described as a "waterflask" contour and is a sign of poor prognosis (104). The remaining modalities are discussed below; Table 2 highlights prognostic variables with cutoffs for negative indicators in $\mathrm{PH}$.

\section{Echo Predictors of Outcome in PH}

Echo is a key means of assessment of PA pressure and cardiac function at baseline diagnosis and for providing prognostic information (156). Multiple independent baseline echo variables, many reflecting RV function have been shown to be associated with survival (157). The most useful echo parameters used to determine prognosis of $\mathrm{PH}$ patients include RA area (149, $150)$, pericardial effusion $(8,150)$, eccentricity index $(150)$, and TAPSE (148).

RA area is closely correlated to the degree of RAP. PAH patients who have RA area $\geq 27 \mathrm{~cm}^{2}$ are at higher risk of mortality or the need for heart transplant than those with a smaller RA area $\left(<27 \mathrm{~cm}^{2}, p<0.001\right)$ (149). The 2015 ESC/ERS guidelines recommend that RA area be used to stratify patients with $\mathrm{PAH}$ who are at risk of clinical worsening or death (26); RA area $<18 \mathrm{~cm}^{2}$ is suggested to confer low risk $(<5 \%), 18-26 \mathrm{~cm}^{2}$ intermediate risk (5$10 \%)$, and $>26 \mathrm{~cm}^{2}$ high risk (>10\%). In an outcomes study of patients with advanced, severe $\mathrm{PH}$, the prognostic 
TABLE 2 | Prognostic parameters in pulmonary hypertension.

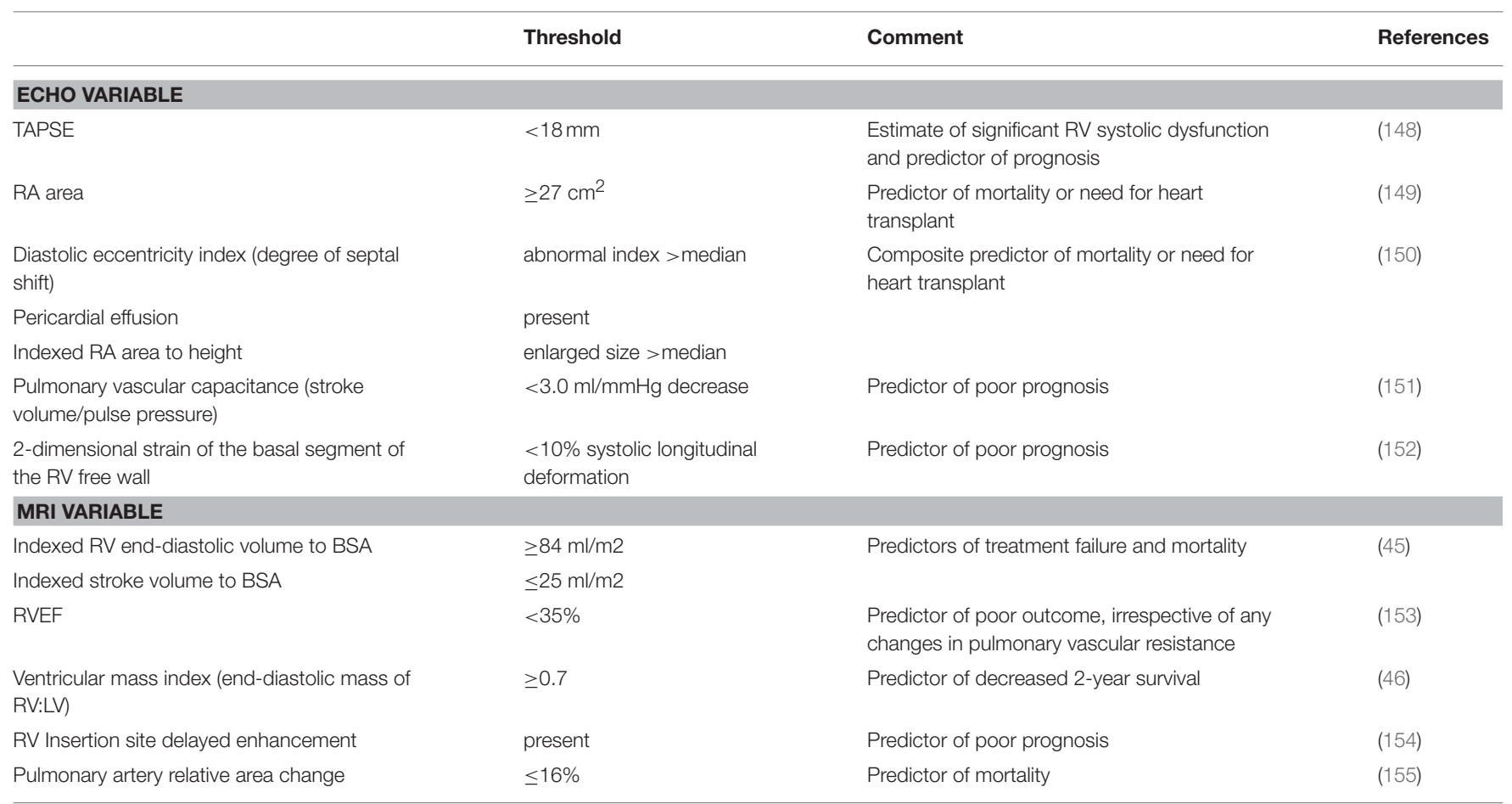

BSA, body surface area; EF, ejection fraction; MRI, magnetic resonance imaging; RA, right atrial; RV, right ventricular; TAPSE, tricuspid annular plane systolic excursion.

significance of several echo abnormalities was described (150). RA area indexed to BSA was shown to be an independent predictor of mortality $(p=0.005)$ among $\mathrm{PAH}$ patients with WHO FC III-IV. Pericardial effusion was also an independent predictor of mortality $(p=0.003)$. Serial TTE can measure pericardial effusion during follow-up that when persistent can be predictive of poorer outcomes (158). Finally, abnormal diastolic eccentricity index (degree of septal shift) and increased RA size indexed to height that were greater than the median in the studied group, in conjunction with presence of pericardial effusion was shown to predict death and/or need for transplantation (150).

RV function is important because it predicts survival (1, $159,160)$. TAPSE provides information about the status of $\mathrm{RV}$ systolic function based on the longitudinal function of RV myocardial fibers (157). In a prospective study (148), $63 \mathrm{PH}$ patients underwent RHC followed by TTE to determine the prognostic significance of TAPSE. TAPSE $<1.8 \mathrm{~cm}$ (compared to that of $\geq 1.8 \mathrm{~cm}$ ) was seen in patients who had more severe RV systolic dysfunction, right heart remodeling, and disproportionate RV size relative to the LV; these patients with TAPSE $<1.8 \mathrm{~cm}$ had significantly lower rates of survival. In $\mathrm{PAH}$ patients with TAPSE $\geq 1.8 \mathrm{~cm}, 1$ - and 2-year survival estimates were 94 and $88 \%$, respectively, compared to 60 and $50 \%$, respectively, when TAPSE $<1.8 \mathrm{~cm}$. TAPSE thus can predict risk of severe disease and death in PAH. Additionally, both low pulmonary vascular capacitance (stroke volume/pulse pressure) (151) and 2D strain of the basal RV free wall (152) have been shown to be predictors of poor prognosis.

\section{Prognostic CMR Parameters and Predictors of Outcome in PH}

CMR can be used to estimate prognosis in $\mathrm{PH}$ in conjunction with disease severity assessment (42, 161). CMR markers that have prognostic value include RV mass, RV volume, and RV function. Increased RV end-diastolic and end-systolic volumes and decreased RVEF indicate the changes that are associated with worse prognosis in patients with $\mathrm{PH}$, despite optimized medical therapy.

Increased RV end-diastolic volume has been suggested as the most precise marker for progressive RV failure (162), and reduced RVSV on CMR has been associated with increased mortality (18); CMR-derived RVSV correlates with the change in 6 -min walk test distance in patients with $\mathrm{PH}(p<0.0001)(163)$. Specific cutoffs for poor prognosis include dilated indexed enddiastolic $\mathrm{RV}$ volume $\geq 84 \mathrm{ml} / \mathrm{m}^{2}$ and reduced indexed $\mathrm{RVSV} \leq 25$ $\mathrm{ml} / \mathrm{m}^{2}(45)$.

A significant relationship has also been shown between CMR measures of RV dysfunction in $\mathrm{PH}$ and serum $\mathrm{N}$-terminal pro-Btype natriuretic peptide (NTpro-BNP), which is released from the ventricle in response to increased pressure or volume overload, and is a highly sensitive and specific biomarker of RV systolic dysfunction (164). One threshold for poor prognosis regarding RV systolic dysfunction is RVEF $\leq 35 \%$ (153). Beyond RVEF ventricular wall motion such as the degree of left septal bowing can be of prognostic value (159).

Elevated ratio of RV end-diastolic mass, compared to LV enddiastolic mass $\geq 0.7$ predicts reduced survival at 2 years (46). Additionally, increased incidence of adverse outcomes has been 
associated with the presence of myocardial DE, in particular at the insertion points of the RV into the septum (154).

Parameters involving the PA can be other useful measurements of prognosis. Prolonged pulmonary mean transit time and decreased pulmonary blood flow measured with DCE MR imaging are more common in patients with PH $(165,166)$ and associated with worse outcomes (161). For example, decreased MPA RAC to $\leq 16 \%$ indicates increased MPA stiffness and is associated with increased mortality (155). PA pulsatility of deformation is another useful measure obtained with CMR and can indicate increased PA stiffness and increased risk of mortality (18).

\section{FOLLOW-UP AND MONITORING OF TREATMENT}

\section{Follow-Up Echo Assessment in PH}

Echo has utility during follow-up, for example on clinical worsening of $\mathrm{PH}$ (167). In patients with established $\mathrm{PH}$, TTE is frequently used to detect the onset of RV dysfunction because of the correlation between progressive RV dysfunction and increasing morbidity and mortality (168). In addition, echo parameters allow monitoring of medical treatment and evaluation of response to therapy $(169,170)$ or outcomes after pulmonary endarterectomy (171). Peak TR velocity (172), TAPSE, RA area (173), and pericardial effusion (158) are clinically relevant variables that can be assessed with echo in follow-up. However, challenges to using echo as a follow-up assessment to guide therapy include difficulties with obtaining reproducible measurements and lack of consistent methods for reporting RV size and function (174).

\section{Follow-Up CMR Assessment in PH}

CMR may overcome some of the major limitations of TTE in the assessment of the RV, as well as avoid the repeat exposure to radioactive tracers that occur with nuclear or CT imaging. The reproducibility of CMR-derived parameters of ventricular function and mass is superior to $2 \mathrm{D}$ echo (175) and makes CMR useful for follow-up. Due to its non-invasive nature and lack of need for ionizing radiation, CMR has become an attractive option for serial assessments of the RV to monitor response to treatment.

Since RV failure is the most common cause of death in $\mathrm{PH}$ patients, it has been argued that serial CMRs can help to monitor treatment response (40). There is prognostic relevance of baseline and follow-up RVEF as measured by CMR in PAH patients (153). A smaller trial (SERAPH study) evaluated the effects of PH therapy on the RV (176). The larger EURO-MR study (177) showed that CMR measurements taken at baseline and during follow-up can provide important information about response to PAH-specific therapy, where CMR measured the effects of treatment on RVEF and LVEF, indexed RVSV and indexed LV end-diastolic volume. Other studies have measured the effects of treatment on RV volumes (42). Contrast-enhanced CMR, using the extracellular contrasting agent gadopentetate dimeglumine, can be used at follow-up to detect fibrosis at the RV insertion points of patients with severe PAH (178).
Other parameters involving the right circulation and the PA can provide follow-up information. Follow-up assessment has also evaluated extent of RV-PA coupling using both CMR (for volume assessment) and RHC (for pressure assessment) $(55,179)$. Severe uncoupling occurs in more severe disease due to a mismatch between increasing arterial load and a failing RV (55). Non-invasive assessment of pulmonary vascular resistance is ideal in this patient population for the assessment of response to therapy and follow-up (180). PC-CMR assessment of PA distensibility has correlated to response to vasodilator therapy, with a threshold of 10\% (100\% sensitivity and 56\% specificity) distinguishing those who responded to those who did not (181).

\section{CT Guidance of and Monitoring Response to Treatment}

CTA can be employed to help determine the success of embolization therapy for pulmonary AVMs (118). Distinction of PVOD and PCH (presence of small, smooth septal lines, geographic and nodular (centrilobular) ground-glass opacities, enlarged lymph nodes, and pleural effusions) from other causes of $\mathrm{PH}$ is critical to ensuring appropriate treatment and referral for lung transplant $(182,183)$. PVOD diagnosis is critical, because the pharmacologic therapy for $\mathrm{PH}$ uses agents that dilate the PA vascular bed. These agents can in turn cause a catastrophic collapse in perfusion pressure to the LH in cases of PVOD, potentially resulting in death.

CTPA is also important in the assessment of CTEPH patients being considered for surgical candidacy (184). While $\mathrm{V} / \mathrm{Q}$ scan is still considered as the initial imaging test of choice for diagnosis of CTEPH (87), once the diagnosis is made or suggested, CTPA is commonly used to assess the extent of disease (Figures 9B-H) and the secondary cardiopulmonary changes. CTPA allows identification of proximal disease and extent of thrombi, which if limited to proximal vessels these patients may be good candidates for surgery. It can also identify distal obstructions, narrowing of the PAs and their branches, and distal stenosis (185). The presence of bronchial artery collaterals also has significance in patients with CTEPH since these patients typically do well postoperatively (186).

\section{THE FUTURE: NEW, EMERGING TECHNIQUES}

Technology advances in recent years have created new imaging sequences in the various four modalities, allowing for closer assessment of myocardial tissue structure and function regarding motion, deformation, and metabolism. More precise visualization of the complex RV anatomy by advanced imaging techniques and accurate measurement of blood volumes and flow may help obviate the need for invasive procedures in the future (187). Table 3 highlights some of the recent advanced tools that have been developed and are being studied. 
TABLE 3 | New non-invasive imaging techniques for pulmonary hypertension (PH).

\begin{tabular}{|c|c|c|}
\hline Modality & Parameter & Comments \\
\hline \multirow[t]{3}{*}{ Echo } & $\begin{array}{l}\text { Speckle-tracking } \\
\text { RV strain (188) }\end{array}$ & $\begin{array}{l}\text { Normal }<-25 \% \text {, definitely abnormal } \\
>-20 \% ; \geq-19 \% \text { is significantly } \\
\text { associated with all-cause mortality }\end{array}$ \\
\hline & $\begin{array}{l}\text { Three-dimensional } \\
\text { echo (3DE) (189) }\end{array}$ & $\begin{array}{l}\text { Comparable correlation to MRI; } \\
\text { real-time 3DE could become a time- } \\
\text { and cost-saving alternative to MRI }\end{array}$ \\
\hline & $\begin{array}{l}\text { Exercise stress } \\
\text { echo (172) }\end{array}$ & $\begin{array}{l}\text { RVSP increase } \leq 30 \mathrm{mmHg} \text { with } \\
\text { exercise suggests worse prognosis }\end{array}$ \\
\hline \multirow[t]{3}{*}{ MRI } & $\begin{array}{l}\text { RV Tagging strain } \\
(190)\end{array}$ & $\begin{array}{l}\text { Predictors of clinical deterioration and } \\
\text { death in patients with } \mathrm{PAH}\end{array}$ \\
\hline & $\begin{array}{l}\text { Fast } \\
\text { strain-encoded } \\
\text { (SENC) imaging } \\
\text { (191) }\end{array}$ & $\begin{array}{l}\text { Real-time through-plane tagging } \\
\text { technique that allows direct } \\
\text { measurement of regional function via } \\
\text { one free-breathing heart beat }\end{array}$ \\
\hline & $\begin{array}{l}\text { RV myocardial T1 } \\
\text { mapping (192) }\end{array}$ & $\begin{array}{l}\text { Enables measurement of myocardial } \\
\text { extracellular volume; may be useful } \\
\text { for detecting early stages of chronic } \\
\mathrm{PH} \text {, prior to onset of overt, } \\
\text { macroscopic fibrosis }\end{array}$ \\
\hline \multirow[t]{2}{*}{ Nuclear \& CT } & RV FDG PET (193) & $\begin{array}{l}\text { Higher uptake is associated with } \\
\text { clinical worsening of } \mathrm{PH} \text { and can be } \\
\text { used in hybrid imaging }\end{array}$ \\
\hline & $\begin{array}{l}\text { Dual-energy CT } \\
\text { (194) }\end{array}$ & $\begin{array}{l}\text { Can provide incremental pulmonary } \\
\text { blood volume maps and be used in } \\
\text { hybrid imaging }\end{array}$ \\
\hline
\end{tabular}

$C T$, computed tomography; Echo, echocardiography; FDG, fluorodeoxyglucose; MRI, magnetic resonance imaging; PAH, pulmonary arterial hypertension; PET, positron emission tomography; RV, right ventricle; RVSP, right ventricular systolic pressure.

\section{Echocardiography: Speckle Tracking, 3D Echo, and Stress Echo}

Software packages have been created with the capability of performing 2D analysis by speckle tracking (195). Speckle tracking can measure strain (myocardial deformation) and strain rate (speed at which deformation occurs) as variables of $\mathrm{RV}$ myocardial injury in $\mathrm{PH}$ (157). As assessed by speckle tracking strain and strain rate, the extent of myocardial damage in $\mathrm{PH}$ can be described as normal deformation due to afterload and contractility increase, reduced deformation due to afterload increase but preserved contractility, and reduced deformation due to afterload increase and reduced contractility. It can measure regional myocardial deformation with good correlation between PH severity and the degree of RV strain reduction (157). Diminished systolic longitudinal strain reflects the severity of RV dysfunction (152). Decreased strain has been shown to be significantly associated with all-cause mortality (188). 2D strain imaging by speckle tracking is volume and load dependent, and needs further standardization, as RV assessments based on $2 \mathrm{D}$ imaging can show variable reproducibility (196).

Real-time 3D echo has shown promise for measuring RV size volume and systolic function (197); it is superior to 2D echo, and can more accurately evaluate RV end-diastolic volume and RVEF $(156,198)$. 3D echo can provide evaluation of the RV without geometric assumptions that are integral to 2D imaging (157). It has been shown that it could provide both time and cost savings compared to MRI (189). There is some evidence that 3D echo and
2D speckle-tracking echo may be better predictors of $\mathrm{RH}$ failure and mortality than traditional echo variables (198). However, sometimes $3 \mathrm{D}$ cannot be performed since the enlarged RV cannot be completely seen within one view (189). Therefore, while 3D $\mathrm{RV}$ echo imaging has been an active area of investigation, this has not yet translated to routine clinical usage (199).

Echo also has capability of being utilized during an exercise stress protocol, such as with bicycle. Physiological response to a moderate amount of exercise results in a decrease in pulmonary vascular resistance and modest increase in MPAP, correlating to increased cardiac output. Normal values of Doppler-derived PASP in normal individuals usually remain $\leq 40 \mathrm{mmHg}$ during exercise (200). Exercise stress Doppler echo has been used to assess exercise- and hypoxia-induced PH (201). PASP during moderate exercise was $<43 \mathrm{mmHg}$ in healthy adults, while in those over 55 years of age, PASP at peak exercise could reach toward $60 \mathrm{mmHg}$ (201). Although exercise pulmonary pressures are not currently included in the criteria for $\mathrm{PH}, \mathrm{PA}$ pressure assessment during exercise can be considered in those with shortness of breath without a known cause who have a normal resting echo to evaluate for a pulmonary hypertensive response to exercise. Finally, loss of RV contractile reserve demonstrated in patients with established $\mathrm{PH}$ who do not have a pressure increase of at least $30 \mathrm{mmHg}$ with exercise suggests a worse prognosis (172). The caveat is the one must keep in mind that it is technically demanding due to the time-sensitive nature of the test (156).

\section{MRI: Strain Tagging, Strain-Encoded Imaging, T1 Mapping, Exercise CMR, Machine Learning, and Quantitative PA Flow Analysis}

While assessment of global ventricular function by traditional CMR techniques have prognostic value for future heart failure (202), they are not sensitive to regionality. There has been a push in recent years to better evaluate changes in regional performance regarding myocardial strain and torsion. Myocardial tagging by CMR can allow for measurement of regional ventricular deformation (191). Tagging tracks differences in CMR signal intensity between tagged and untagged areas of tissue, applying mathematical formulae to reconstruct a 3D image of the heart (203). Strain analysis can be useful for identifying early changes in $\mathrm{RV}$ function before overt reductions in global RV function and ventricular dyssynchrony manifest (204). In PAH, RV strain and strain rate have been demonstrated to be predictors of $\mathrm{RH}$ failure and mortality (190).

The technique of fast strain-encoded (SENC) imaging can evaluate regional biventricular strain to detect regional $\mathrm{RV}$ dysfunction in those with normal global RV function (191). $\mathrm{RV}$ strain mapping provides quantitative evaluation of regional myocardial function, increasing the sensitivity of CMR to find regional abnormalities in RV function.

T1 mapping provides measurements of intrinsic longitudinal relaxation time of tissue. The technique applied to the RV can identify diffuse myocardial pathologic processes in the setting of $\mathrm{PH}$, specifically in the interstitium. Measurement 
of RV myocardial T1 before and after the receipt of GBCA allows for quantification of the extracellular volume. It has been shown that RV T1 mapping values correlate with pulmonary hemodynamics, RV-PA coupling, and RV performance (192), and are associated with indicators of RV dysfunction $(192,205)$. Increased pre-contrast $\mathrm{T} 1$ values at interventricular insertion points on native T1 mapping has been demonstrated in precapillary PH (206). RV T1 mapping has promise in the detection of diffuse myocardial fibrosis in RV failure, a crucial end result in $\mathrm{PH}$, and thus RV T1 mapping may have utility in determining treatment response in $\mathrm{PH}$.

Additionally, there has been some work done in the realm of exercise CMR (207), including more recently a methodology using exercise stress CMR to measure changes in MPA RAC as a surrogate of MPA stiffness, which offers the potential to better understand the mechanisms that contribute to exerciseinduced $\mathrm{PH}$ and exercise tolerance in those with $\mathrm{PH}$ (67, 208). Nevertheless, logistical challenges with the availability of MRI-conditional or -compatible stress equipment and the time-sensitive nature of obtaining CMR images during and immediately after exercise remain.

Finally, new frontiers of CMR involve quantitative analysis of helicity and vorticity of PA flow in $\mathrm{PH}$ patients, demonstrating a strong association between helicity in the PAs and ventriclevessel coupling (209), and machine learning of 3D RV wall motion, which is beginning to enable the prediction of outcome and survival in those newly diagnosed with $\mathrm{PH}$, independent of traditional risk factors (210).

These novel imaging approaches can provide unique insight into the pathophysiology of $\mathrm{PH}$, and their incremental utility should be examined in prospective research studies (including $\mathrm{PH}$ clinical trials) to determine their utility relative to conventional imaging approaches. However, one area of ongoing limited utility with MRI remains the assessment of lung parenchyma. While newer sequences including ultra-short echo time imaging show potential, these remain still in their early stages, and more studies are needed (211).

\section{CT: Dual-Energy}

New-generation CT scanners are capable to perform dual-energy CT (DECT), either with two x-ray sources and two detectors (DSCT) or with one x-ray source and one detector (212). DECT provides the same vascular and lung parenchymal findings as conventional CT, including PA diameter and morphology, but with incremental perfusion analysis information of the lungs $(212,213)$ via iodine maps fused with nuclear scintigraphy information to create lung-vessel maps (see Nuclear-CT Hybrid Imaging). Pulmonary parenchymal morphology, vascular anatomy, and functional assessment can all potentially be obtained in one test.

Single-source DECT involves rapidly switching kilovoltage (low, around $80 \mathrm{kVp}$, and high, around $140 \mathrm{kVp}$ ) at the $\mathrm{x}$-ray tube anode with sophisticated detectors that can simultaneously separate photons of different energies, in order to exploit the differences in iodine attenuation at these different kilovoltages. DECT allows the scanner to quantitatively characterize the properties of various tissues, such as separating materials like iodine and calcium. Using a standard CTPA scan, DECT has been used to make quantitative lung perfusion and pulmonary blood volume (PBV) maps $(212,214-216)$ by calculating the amount of iodine in a voxel. While these PBV maps are not exactly perfusion images as they are a measurement of iodine at one time point while the scan is being acquired, they can serve as a sufficient surrogate marker of lung perfusion (194). In CTEPH, PBV maps have been used to assess pulmonary hemodynamics and surgical candidacy; there was a trend of inverse correlation between PBV values and pulmonary vascular resistance (217). DECT can also show evidence of bronchial collateral supply, a good prognostic marker in CTEPH (218).

\section{Hybrid Imaging}

Digital radiological imaging systems in the modern day have the capability for concurrent fusion of images across multiple modalities, forming combined studies with both high spatial and contrast resolution (219). Multiple variables can be characterized simultaneously in a single study with optimal co-registration.

\section{Nuclear-CT \\ SPECT/CT}

SPECT and CT have more recently become merged to integrate function and perfusion information from SPECT with anatomic information from CT. SPECT/CT can merge regional lung perfusion data with $3 \mathrm{D}$ images to depict PA structures with pulmonary perfusion, thus to identify segments of pulmonary hypoperfusion (220), useful in the evaluation of CTEPH (221). Another study comparing those with pre-capillary $\mathrm{PH}$ and healthy controls calculated a perfusion redistribution index (PRI) via SPECT/CT (222). The PRI quantified gravity-dependent shifts in regional lung perfusion as a marker of pulmonary vascular reserve. The PRI was significantly reduced in those with pre-capillary $\mathrm{PH}$ compared to controls; the index was associated with several prognostic factors. However, SPECT/CT may underappreciate the actual extent of vascular obstruction in CTEPH (223). Therefore, the incremental utility of SPECT/CT is still being determined, and thus comparison to more traditional techniques needs to be further investigated in order for SPECT/CT to be properly assimilated into real-world practice.

\section{PET/CT}

PET has higher spatial resolution than SPECT and allows for attenuation correction, yielding improved RV visualization and potential for quantifying utilization of metabolic substrates (224). In addition to abnormal RV perfusion, impairment of RV metabolism is another major determinant of $\mathrm{RH}$ failure in $\mathrm{PH}$ patients (225). In $\mathrm{PH},{ }^{18} \mathrm{~F}$ FDG accumulation, a measure of the rate of glycolysis, has been shown to be elevated in the RV free wall (226). Higher uptake is associated with clinical worsening of $\mathrm{PH}$ (193). It has been argued that PET can assess PH severity and clinical outcome (227), thus providing a method to evaluate treatment response (225). The combination of PET and CT imaging in a single camera system provides integrated anatomical and pathological correlation of abnormal function, perfusion, and/or metabolic processes, with the fusion of both image modalities facilitating the interpretation of each 
other. Attenuation maps from the CT is used to optimize attenuation correction of the PET. Nevertheless, while the feasibility of PET has been shown in patients with $\mathrm{PH}$, there have been heterogeneous results and the production of high-quality research regarding the utility of measuring metabolic shift in $\mathrm{RV}$ dysfunction in the setting of $\mathrm{PH}$ is still ongoing before its implementation in routine clinical practice (228).

\section{PET-MRI}

The anatomical information from MRI can be combined with the functional information from PET. This allows for the simultaneous acquisition of structure, function, perfusion, tissue characterization, and flow imaging, setting up for improved understanding of the RH-PA system (229).

\section{CONCLUSION}

Multimodality non-invasive imaging of the RH-PA plays a vital role in the evaluation and management of $\mathrm{PH}$. The imaging techniques that are used for $\mathrm{PH}$ are various with strengths and limitations; with the aim of value-based decision-making, a judicious step-wise approach algorithm to utilization of imaging in $\mathrm{PH}$ evaluation may reduce unnecessary testing and improve the value of care.

CXR is commonly used in the initial evaluation of PH. Echo is an established, reliable, and relatively low-cost tool to initially appraise the heart in suspected $\mathrm{PH}$; specifically, it can be used to evaluate for $\mathrm{PH}$ due to $\mathrm{LH}$ disease, the most common cause of $\mathrm{PH}$ in the developed world. V/Q scan is most useful in identifying CTEPH patients, identifying mismatched perfusion defects. Cross-sectional MRI and CT imaging contributes to etiology determination and pathophysiology characterization of PH. CT can examine the lung parenchyma and help elucidate contributing causes due to pulmonary disease and

\section{REFERENCES}

1. Badesch DB, Champion HC, Sanchez MA, Hoeper MM, Loyd JE, Manes A, et al. Diagnosis and assessment of pulmonary arterial hypertension. J Am Coll Cardiol. (2009) 54(1 Suppl.):S55-66. doi: 10.1016/j.jacc.200 9.04 .011

2. Runo JR, Loyd JE. Primary pulmonary hypertension. Lancet. (2003) 361:1533-44. doi: 10.1016/S0140-6736(03)13167-4

3. Simonneau G, Gatzoulis MA, Adatia I, Celermajer D, Denton C, Ghofrani A, et al. Updated clinical classification of pulmonary hypertension. J Am Coll Cardiol. (2013) 62(25 Suppl):D34-41. doi: 10.1016/j.jacc.2013.10.029

4. Dellegrottaglie S, Ostenfeld E, Sanz J, Scatteia A, Perrone-Filardi P, Bossone E. Imaging the right heart-pulmonary circulation unit: the role of MRI and computed tomography. Heart Failure Clin. (2014) 14:377-91. doi: 10.1016/j.hfc.2018.03.004

5. Raymond TE, Khabbaza JE, Yadav R, Tonelli AR. Significance of main pulmonary artery dilation on imaging studies. Ann Am Thorac Soc. (2014) 11:1623-32. doi: 10.1513/AnnalsATS.201406-253PP

6. Farber HW, Miller DP, Poms AD, Badesch DB, Frost AE, Muros-Le Rouzic E, et al. Five-Year outcomes of patients enrolled in the REVEAL Registry. Chest. (2015) 148:1043-54. doi: 10.1378/chest.15-0300

7. Humbert M, Sitbon O, Chaouat A, Bertocchi M, Habib G, Gressin $\mathrm{V}$, et al. Survival in patients with idiopathic, familial, and anorexigenassociated pulmonary arterial hypertension in the modern management era. other multifactorial conditions. MRI, with its ability to provide complementary information to echo, as well as incremental value regarding tissue characterization, is becoming increasingly utilized. Radionuclide nuclear cardiology studies can be used in select situations to provide information regarding function, perfusion, and metabolism.

Early disease recognition remains one of the essential challenges for future advances in imaging. Novel imaging techniques in the various modalities, including integration across modalities via hybrid imaging continue to be developed and investigated to allow for such early disease detection, which may allow for earlier preventive and therapeutic approaches to be adopted. Currently, their exact role in the diagnostic and followup evaluation of $\mathrm{PH}$ remains unclear, and thus additional studies are needed to clarify their role. Nevertheless, the development of more advanced imaging tools will hopefully increase our understanding of the pathophysiological factors related to the $\mathrm{RH}$ and the vascular biology of the PA circulation that lead to $\mathrm{RV}$ failure in $\mathrm{PH}$; advances in spatial resolution, contrast perfusion, tissue characterization, and flow analysis will allow for the continued study and subsequent optimization in refining the role of non-invasive imaging for the detection and management of $\mathrm{PH}$ in the future. This is with the aim of perfecting their role in making the diagnosis, as well as enhancing future clinical trials regarding the response to treatment, thus guiding the management and follow-up of $\mathrm{PH}$ after therapy. Then that could ultimately the change the incidence, and morbid and deadly clinical manifestations of $\mathrm{PH}$.

\section{AUTHOR CONTRIBUTIONS}

$\mathrm{DH}$ collected articles and devised the manuscript in collaboration with LS. Both authors critically reviewed, revised, and approved the final manuscript.
Circulation. (2010) 122:156-63. doi: 10.1161/CIRCULATIONAHA.109.9 11818

8. Benza RL, Miller DP, Gomberg-Maitland M, Frantz RP, Foreman AJ, Coffey CS, et al. Predicting survival in pulmonary arterial hypertension: insights from the Registry to Evaluate Early and Long-Term Pulmonary Arterial Hypertension Disease Management (REVEAL). Circulation. (2010) 122:16472. doi: 10.1161/CIRCULATIONAHA.109.898122

9. Humbert M, Gerry Coghlan J, Khanna D. Early detection and management of pulmonary arterial hypertension. Eur Respir Rev. (2012) 21:306-12. doi: 10.1183/09059180.00005112

10. Tonelli AR, Arelli V, Minai OA, Newman J, Bair N, Heresi GA, et al. Causes and circumstances of death in pulmonary arterial hypertension. Am J Respir Crit Care Med. (2013) 188:365-9. doi: 10.1164/rccm.201209-1640OC

11. Schulze-Neick I, Lange PE, Haas NA. Intravenous epoprostenol for primary pulmonary hypertension. $N$ Engl J Med. (1996) 334:1477; author reply -8

12. Savarese G, Paolillo S, Costanzo P, D’Amore C, Cecere M, Losco T, et al. Do changes of 6-minute walk distance predict clinical events in patients with pulmonary arterial hypertension? A meta-analysis of 22 randomized trials. $J$ Am Coll Cardiol. (2012) 60:1192-201. doi: 10.1016/j.jacc.2012.01.083

13. Voelkel NF, Quaife RA, Leinwand LA, Barst RJ, McGoon MD, Meldrum $\mathrm{DR}$, et al. Right ventricular function and failure: report of a National Heart, Lung, and Blood Institute working group on cellular and molecular mechanisms of right heart failure. Circulation. (2006) 114:1883-91. doi: 10.1161/CIRCULATIONAHA.106.632208 
14. Matthews JC, McLaughlin V. Acute right ventricular failure in the setting of acute pulmonary embolism or chronic pulmonary hypertension: a detailed review of the pathophysiology, diagnosis, and management. Curr Cardiol Rev. (2008) 4:49-59. doi: 10.2174/157340308783565384

15. Haddad F, Hunt SA, Rosenthal DN, Murphy DJ. Right ventricular function in cardiovascular disease, part I: Anatomy, physiology, aging, and functional assessment of the right ventricle. Circulation. (2008) 117:1436-48. doi: 10.1161/CIRCULATIONAHA.107.653576

16. Rudski LG, Lai WW, Afilalo J, Hua L, Handschumacher MD, Chandrasekaran $\mathrm{K}$, et al. Guidelines for the echocardiographic assessment of the right heart in adults: a report from the American Society of Echocardiography endorsed by the European Association of Echocardiography, a registered branch of the European Society of Cardiology, and the Canadian Society of Echocardiography. J Am Soc Echocardiogr. (2010) 23:685-713; quiz 86-8. doi: 10.1016/j.echo.2010.05.010

17. Chesler NC, Roldan A, Vanderpool RR, Naeije R. How to measure pulmonary vascular and right ventricular function. Conf Proc IEEE Eng Med Biol Soc. (2009) 2009:177-80. doi: 10.1109/IEMBS.2009.5333835

18. Freed BH, Collins JD, Francois CJ, Barker AJ, Cuttica MJ, Chesler NC, et al. $\mathrm{MR}$ and CT imaging for the evaluation of pulmonary hypertension. JACC Cardiovasc Imaging. (2016) 9:715-32. doi: 10.1016/j.jcmg.2015.12.015

19. Kerr IH. Vascular changes in the lungs on the plain radiograph of the chest. Postgrad Med J. (1970) 46:3-10.

20. Brown K, Gutierrez AJ, Mohammed TL, Kirsch J, Chung JH, Dyer DS, et al. ACR Appropriateness Criteria(R) pulmonary hypertension. J Thorac Imaging. (2013) 28:W57-60. doi: 10.1097/RTI.0b013e31829191b5

21. Schmidt HC, Kauczor HU, Schild HH, Renner C, Kirchhoff E, Lang $\mathrm{P}$, et al. Pulmonary hypertension in patients with chronic pulmonary thromboembolism: chest radiograph and CT evaluation before and after surgery. Eur Radiol. (1996) 6:817-25.

22. Fleischner FG. Pulmonary embolism. Clin Radiol. (1962) 13:169-82.

23. Helmberger M, Pienn M, Urschler M, Kullnig P, Stollberger R, Kovacs $\mathrm{G}$, et al. Quantification of tortuosity and fractal dimension of the lung vessels in pulmonary hypertension patients. PLoS ONE. (2014) 9:e87515. doi: 10.1371/journal.pone.0087515

24. Frazier AA, Burke AP. The imaging of pulmonary hypertension. Semin Ultras CT MR. (2012) 33:535-51. doi: 10.1053/j.sult.2012.06.002

25. Milne EN. Forgotten gold in diagnosing pulmonary hypertension: the plain chest radiograph. Radiographics. (2012) 32:1085-7. doi: 10.1148/rg.324125021

26. Galie N, Humbert M, Vachiery JL, Gibbs S, Lang I, Torbicki A, et al. 2015 ESC/ERS Guidelines for the diagnosis and treatment of pulmonary hypertension: the joint task force for the diagnosis and treatment of pulmonary hypertension of the European Society of Cardiology (ESC) and the European Respiratory Society (ERS): Endorsed by: Association for European Paediatric and Congenital Cardiology (AEPC), International Society for Heart and Lung Transplantation (ISHLT). Eur Respir J. (2015) 46:903-75. doi: 10.1183/13993003.01032-2015

27. Moceri P, Baudouy D, Chiche O, Cerboni P, Bouvier P, Chaussade C, et al. Imaging in pulmonary hypertension: Focus on the role of echocardiography. Arch Cardiovasc Dis. (2014) 107:261-71. doi: 10.1016/j.acvd.201 4.02.005

28. Hoeper MM, Bogaard HJ, Condliffe R, Frantz R, Khanna D, Kurzyna M, et al. Definitions and diagnosis of pulmonary hypertension. J Am Coll Cardiol. (2013) 62(25 Suppl):D42-50. doi: 10.1016/j.jacc.2013.10.032

29. Barst RJ, McGoon M, Torbicki A, Sitbon O, Krowka MJ, Olschewski $\mathrm{H}$, et al. Diagnosis and differential assessment of pulmonary arterial hypertension. J Am Coll Cardiol. (2004) 43(12 Suppl S):40S-7S. doi: 10.1016/j.jacc.2004.02.032

30. McGoon M, Gutterman D, Steen V, Barst R, McCrory DC, Fortin TA, et al. Screening, early detection, and diagnosis of pulmonary arterial hypertension: ACCP evidence-based clinical practice guidelines. Chest. (2004) 126(1 Suppl):14S-34S. doi: 10.1378/chest.126.1_suppl.14S

31. Lang RM, Badano LP, Mor-Avi V, Afilalo J, Armstrong A, Ernande L, et al. Recommendations for cardiac chamber quantification by echocardiography in adults: an update from the American Society of Echocardiography and the European Association of Cardiovascular Imaging. J Am Soc Echocardiogr. (2015) 28:1-39 e14. doi: 10.1016/j.echo.2014.10.003
32. Rogers JH, Bolling SF. The tricuspid valve: current perspective and evolving management of tricuspid regurgitation. Circulation. (2009) 119:2718-25. doi: 10.1161/CIRCULATIONAHA.108.842773

33. Howard LS, Grapsa J, Dawson D, Bellamy M, Chambers JB, Masani ND, et al. Echocardiographic assessment of pulmonary hypertension: standard operating procedure. Eur Respir Rev. (2012) 21:239-48. doi: 10.1183/09059180.00003912

34. Moreno FL, Hagan AD, Holmen JR, Pryor TA, Strickland RD, Castle CH. Evaluation of size and dynamics of the inferior vena cava as an index of right-sided cardiac function. Am J Cardiol. (1984) 53:579-85

35. Brennan JM, Blair JE, Goonewardena S, Ronan A, Shah D, Vasaiwala $\mathrm{S}$, et al. Reappraisal of the use of inferior vena cava for estimating right atrial pressure. J Am Soc Echocardiogr. (2007) 20:857-61. doi: 10.1016/j.echo.2007.01.005

36. Greiner S, Jud A, Aurich M, Hess A, Hilbel T, Hardt S, et al. Reliability of noninvasive assessment of systolic pulmonary artery pressure by Doppler echocardiography compared to right heart catheterization: analysis in a large patient population. J Am Heart Assoc. (2014) 3:e001103. doi: 10.1161/JAHA.114.001103

37. Dabestani A, Mahan G, Gardin JM, Takenaka K, Burn C, Allfie A, et al. Evaluation of pulmonary artery pressure and resistance by pulsed Doppler echocardiography. Am J Cardiol. (1987) 59:662-8.

38. Abbas AE, Fortuin FD, Schiller NB, Appleton CP, Moreno CA, Lester SJ. Echocardiographic determination of mean pulmonary artery pressure. Am J Cardiol. (2003) 92:1373-6. doi: 10.1016/j.amjcard.2003.08.037

39. Scalia GM, Scalia IG, Kierle R, Beaumont R, Cross DB, Feenstra J, et al. ePLAR - The echocardiographic Pulmonary to Left Atrial Ratio - A novel non-invasive parameter to differentiate pre-capillary and post-capillary pulmonary hypertension. Int J Cardiol. (2016) 212:379-86. doi: 10.1016/j.ijcard.2016.03.035

40. Pena E, Dennie C, Veinot J, Muniz SH. Pulmonary hypertension: how the radiologist can help. Radiographics. (2012) 32:9-32. doi: 10.1148/rg.321105232

41. Marrone G, Mamone G, Luca A, Vitulo P, Bertani A, Pilato M, et al. The role of $1.5 \mathrm{~T}$ cardiac MRI in the diagnosis, prognosis and management of pulmonary arterial hypertension. Int J Cardiovasc Imaging. (2010) 26:66581. doi: $10.1007 /$ s10554-010-9623-2

42. Peacock AJ, Vonk Noordegraaf A. Cardiac magnetic resonance imaging in pulmonary arterial hypertension. Eur Respir Rev. (2013) 22:526-34. doi: 10.1183/09059180. 00006313

43. McMurray JJ, Adamopoulos S, Anker SD, Auricchio A, Bohm M, Dickstein $\mathrm{K}$, et al. ESC guidelines for the diagnosis and treatment of acute and chronic heart failure 2012: The Task Force for the Diagnosis and Treatment of Acute and Chronic Heart Failure 2012 of the European Society of Cardiology. Developed in collaboration with the Heart Failure Association (HFA) of the ESC. Eur J Heart Fail. (2012) 14:803-69. doi: 10.1093/eurjhf/hfs105

44. Benza R, Biederman R, Murali S, Gupta H. Role of cardiac magnetic resonance imaging in the management of patients with pulmonary arterial hypertension. J Am Coll Cardiol. (2008) 52:1683-92. doi: 10.1016/j.jacc.2008. 08.033

45. van Wolferen SA, Marcus JT, Boonstra A, Marques KM, Bronzwaer JG, Spreeuwenberg MD, et al. Prognostic value of right ventricular mass, volume, and function in idiopathic pulmonary arterial hypertension. Eur Heart J. (2007) 28:1250-7. doi: 10.1093/eurheartj/ehl477

46. Hagger D, Condliffe R, Woodhouse N, Elliot CA, Armstrong IJ, Davies C, et al. Ventricular mass index correlates with pulmonary artery pressure and predicts survival in suspected systemic sclerosis-associated pulmonary arterial hypertension. Rheumatology (Oxford). (2009) 48:1137-42. doi: 10.1093/rheumatology /kep187

47. Marcus JT, Gan CT, Zwanenburg JJ, Boonstra A, Allaart CP, Gotte MJ, et al. Interventricular mechanical asynchrony in pulmonary arterial hypertension: left-to-right delay in peak shortening is related to right ventricular overload and left ventricular underfilling. J Am Coll Cardiol. (2008) 51:750-7. doi: 10.1016/j.jacc.2007.10.041

48. McLure LE, Peacock AJ. Cardiac magnetic resonance imaging for the assessment of the heart and pulmonary circulation in pulmonary 
hypertension. Eur Respir J. (2009) 33:1454-66. doi: 10.1183/09031936.00 139907

49. Alunni JP, Degano B, Arnaud C, Tetu L, Blot-Souletie N, Didier A, et al. Cardiac MRI in pulmonary artery hypertension: correlations between morphological and functional parameters and invasive measurements. Eur Radiol. (2010) 20:1149-59. doi: 10.1007/s00330-009-1664-3

50. Blyth KG, Groenning BA, Martin TN, Foster JE, Mark PB, Dargie HJ, et al. Contrast enhanced-cardiovascular magnetic resonance imaging in patients with pulmonary hypertension. Eur Heart J. (2005) 26:1993-9. doi: 10.1093/eurheartj/ehi328

51. McCann GP, Gan CT, Beek AM, Niessen HW, Vonk Noordegraaf A, van Rossum AC. Extent of MRI delayed enhancement of myocardial mass is related to right ventricular dysfunction in pulmonary artery hypertension. AJR Am J Roentgenol. (2007) 188:349-55. doi: 10.2214/AJR.05.1259

52. Swift AJ, Rajaram S, Capener D, Elliot C, Condliffe R, Wild JM, et al. LGE patterns in pulmonary hypertension do not impact overall mortality. JACC Cardiovasc Imaging. (2014) 7:1209-17. doi: 10.1016/j.jcmg.2014.08.014

53. Shehata ML, Lossnitzer D, Skrok J, Boyce D, Lechtzin N, Mathai SC, et al. Myocardial delayed enhancement in pulmonary hypertension: pulmonary hemodynamics, right ventricular function, and remodeling. AJR Am J Roentgenol. (2011) 196:87-94. doi: 10.2214/AJR.09.4114

54. Sato T, Tsujino I, Ohira H, Oyama-Manabe N, Ito YM, Noguchi $\mathrm{T}$, et al. Paradoxical interventricular septal motion as a major determinant of late gadolinium enhancement in ventricular insertion points in pulmonary hypertension. PLoS ONE. (2013) 8(6):e66724. doi: 10.1371/journal.pone.0066724

55. Sanz J, Garcia-Alvarez A, Fernandez-Friera L, Nair A, Mirelis JG, Sawit ST, et al. Right ventriculo-arterial coupling in pulmonary hypertension: a magnetic resonance study. Heart. (2012) 98:238-43. doi: 10.1136/heartjnl-2011-300462

56. Torbicki A. Cardiac magnetic resonance in pulmonary arterial hypertension: a step in the right direction. Eur Heart J. (2007) 28:1187-9. doi: 10.1093/eurheartj/ehm074

57. Nayak KS, Nielsen JF, Bernstein MA, Markl M, P DG, R MB, et al. Cardiovascular magnetic resonance phase contrast imaging. J Cardiovasc Magn Reson. (2015) 17:71. doi: 10.1186/s12968-015-0172-7

58. Gefter WB, Hatabu H. Evaluation of pulmonary vascular anatomy and blood flow by magnetic resonance. J Thorac Imaging. (1993) 8:122-36.

59. Hoeper MM, Tongers J, Leppert A, Baus S, Maier R, Lotz J. Evaluation of right ventricular performance with a right ventricular ejection fraction thermodilution catheter and MRI in patients with pulmonary hypertension. Chest. (2001) 120:502-7. doi: 10.1378/chest.120.2.502

60. Sanz J, Kuschnir P, Rius T, Salguero R, Sulica R, Einstein AJ, et al. Pulmonary arterial hypertension: noninvasive detection with phasecontrast MR imaging. Radiology. (2007) 243:70-9. doi: 10.1148/radiol.24310 60477

61. Sanz J, Kariisa M, Dellegrottaglie S, Prat-Gonzalez S, Garcia MJ, Fuster V, et al. Evaluation of pulmonary artery stiffness in pulmonary hypertension with cardiac magnetic resonance. JACC Cardiovasc Imaging. (2009) 2:28695. doi: 10.1016/j.jcmg.2008.08.007

62. Bellofiore A, Chesler NC. Methods for measuring right ventricular function and hemodynamic coupling with the pulmonary vasculature. Ann Biomed Eng. (2013) 41:1384-98. doi: 10.1007/s10439-013-0752-3

63. van Wolferen SA, Marcus JT, Westerhof N, Spreeuwenberg MD, Marques $\mathrm{KM}$, Bronzwaer JG, et al. Right coronary artery flow impairment in patients with pulmonary hypertension. Eur Heart J. (2008) 29:120-7. doi: 10.1093/eurheartj/ehm567

64. Frydrychowicz A, Francois CJ, Turski PA. Four-dimensional phase contrast magnetic resonance angiography: potential clinical applications. Eur J Radiol. (2011) 80:24-35. doi: 10.1016/j.ejrad.2011.01.094

65. Ibrahim el SH, Shaffer JM, White RD. Assessment of pulmonary artery stiffness using velocity-encoding magnetic resonance imaging: evaluation of techniques. Magn Reson Imaging. (2011) 29:966-74. doi: 10.1016/j.mri.2011.04.012

66. Poon CY, Edwards JM, Evans CJ, Harris AD, Tsai-Goodman B, Bolton $\mathrm{CE}$, et al. Assessment of pulmonary artery pulse wave velocity in children: an MRI pilot study. Magn Reson Imaging. (2013) 31:1690-4. doi: 10.1016/j.mri.2013.08.006
67. Forouzan O, Warczytowa J, Wieben O, Francois CJ, Chesler NC. Noninvasive measurement using cardiovascular magnetic resonance of changes in pulmonary artery stiffness with exercise. J Cardiovasc Magn Reson. (2015) 17:109. doi: 10.1186/s12968-015-0213-2

68. Reiter G, Reiter U, Kovacs G, Kainz B, Schmidt K, Maier R, et al. Magnetic resonance-derived 3-dimensional blood flow patterns in the main pulmonary artery as a marker of pulmonary hypertension and a measure of elevated mean pulmonary arterial pressure. Circ Cardiovasc Imaging. (2008) 1:23-30. doi: 10.1161/CIRCIMAGING.108.780247

69. Reiter U, Reiter G, Kovacs G, Stalder AF, Gulsun MA, Greiser A, et al. Evaluation of elevated mean pulmonary arterial pressure based on magnetic resonance $4 \mathrm{D}$ velocity mapping: comparison of visualization techniques. PLoS ONE. (2013) 8(12):e82212. doi: 10.1371/journal.pone.0082212

70. Tang BT, Pickard SS, Chan FP, Tsao PS, Taylor CA, Feinstein JA. Wall shear stress is decreased in the pulmonary arteries of patients with pulmonary arterial hypertension: An image-based, computational fluid dynamics study. Pulm Circ. (2012) 2:470-6. doi: 10.4103/2045-8932.105035

71. Truong U, Fonseca B, Dunning J, Burgett S, Lanning C, Ivy DD, et al. Wall shear stress measured by phase contrast cardiovascular magnetic resonance in children and adolescents with pulmonary arterial hypertension. J Cardiovasc Magn Reson. (2013) 15:81. doi: 10.1186/1532-429X-15-81

72. Wang Z, Lakes RS, Golob M, Eickhoff JC, Chesler NC. Changes in large pulmonary arterial viscoelasticity in chronic pulmonary hypertension. PLoS ONE. (2013) 8(11):e78569. doi: 10.1371/journal.pone.0078569

73. Barker AJ, Roldan-Alzate A, Entezari P, Shah SJ, Chesler NC, Wieben O, et al. Four-dimensional flow assessment of pulmonary artery flow and wall shear stress in adult pulmonary arterial hypertension: results from two institutions. Magn Reson Med. (2015) 73:1904-13. doi: 10.1002/mrm.25326

74. Nordmeyer S, Riesenkampff E, Crelier G, Khasheei A, Schnackenburg B, Berger $F$, et al. Flow-sensitive four-dimensional cine magnetic resonance imaging for offline blood flow quantification in multiple vessels: a validation study. J Magn Reson Imaging. (2010) 32:677-83. doi: 10.1002/jmri.22280

75. Markl M, Wallis W, Harloff A. Reproducibility of flow and wall shear stress analysis using flow-sensitive four-dimensional MRI. J Magn Reson Imaging. (2011) 33:988-94. doi: 10.1002/jmri.22519

76. Gan C, Lankhaar JW, Marcus JT, Westerhof N, Marques KM, Bronzwaer JG, et al. Impaired left ventricular filling due to rightto-left ventricular interaction in patients with pulmonary arterial hypertension. Am J Physiol Heart Circ Physiol. (2006) 290(4):H1528-33. doi: 10.1152/ajpheart.01031.2005

77. Haddad F, Guihaire J, Skhiri M, Denault AY, Mercier O, Al-Halabi $\mathrm{S}$, et al. Septal curvature is marker of hemodynamic, anatomical, and electromechanical ventricular interdependence in patients with pulmonary arterial hypertension. Echocardiography. (2014) 31:699-707. doi: 10.1111/echo.12468

78. Kuehne T, Yilmaz S, Steendijk P, Moore P, Groenink M, Saaed $\mathrm{M}$, et al. Magnetic resonance imaging analysis of right ventricular pressure-volume loops: in vivo validation and clinical application in patients with pulmonary hypertension. Circulation. (2004) 110:2010-6. doi: 10.1161/01.CIR.0000143138.02493.DD

79. Sun Z, Choo GH, Ng KH. Coronary CT angiography: current status and continuing challenges. Br J Radiol. (2012) 85:495-510. doi: 10.1259/bjr/15296170

80. Ferguson EC, Berkowitz EA. Lung CT: Part 2, The interstitial pneumoniasclinical, histologic, and CT manifestations. AJR Am J Roentgenol. (2012) 199:W464-76. doi: 10.2214/AJR.10.7309

81. Lynch DA, Austin JH, Hogg JC, Grenier PA, Kauczor HU, Bankier AA, et al. CT-Definable Subtypes of Chronic Obstructive Pulmonary Disease: A Statement of the Fleischner Society. Radiology. (2015) 277:192-205. doi: 10.1148/radiol.2015141579

82. Smith BM, Austin JH, Newell JD Jr, D'Souza BM, Rozenshtein A, Hoffman EA, et al. Pulmonary emphysema subtypes on computed tomography: the MESA COPD study. Am J Med. (2014) 127:94 e7-23. doi: 10.1016/j.amjmed.2013.09.020

83. McDonough JE, Yuan R, Suzuki M, Seyednejad N, Elliott WM, Sanchez PG, et al. Small-airway obstruction and emphysema in chronic obstructive pulmonary disease. N Engl J Med. (2011) 365:1567-75. doi: 10.1056/NEJMoa1106955 
84. Miura A, Akagi S, Nakamura K, Ohta-Ogo K, Hashimoto K, Nagase $\mathrm{S}$, et al. Different sizes of centrilobular ground-glass opacities in chest high-resolution computed tomography of patients with pulmonary venoocclusive disease and patients with pulmonary capillary hemangiomatosis. Cardiovasc Pathol. (2013) 22:287-93. doi: 10.1016/j.carpath.2012.12.002

85. Truong QA, Massaro JM, Rogers IS, Mahabadi AA, Kriegel MF, Fox CS, et al. Reference values for normal pulmonary artery dimensions by noncontrast cardiac computed tomography: the Framingham Heart Study. Circ Cardiovasc Imaging. (2012) 5:147-54. doi: 10.1161/CIRCIMAGING.111.968610

86. Ceriani E, Combescure C, Le Gal G, Nendaz M, Perneger T, Bounameaux H, et al. Clinical prediction rules for pulmonary embolism: a systematic review and meta-analysis. J Thromb Haemost. (2010) 8:957-70. doi: 10.1111/j.1538-7836.2010.03801.x

87. Tunariu N, Gibbs SJ, Win Z, Gin-Sing W, Graham A, Gishen P, et al. Ventilation-perfusion scintigraphy is more sensitive than multidetector CTPA in detecting chronic thromboembolic pulmonary disease as a treatable cause of pulmonary hypertension. J Nucl Med. (2007) 48:680-4. doi: 10.2967/jnumed.106.039438

88. Bolen MA, Renapurkar RD, Popovic ZB, Heresi GA, Flamm SD, Lau CT, et al. High-pitch ECG-synchronized pulmonary CT angiography versus standard CT pulmonary angiography: a prospective randomized study. AJR Am J Roentgenol. (2013) 201:971-6. doi: 10.2214/AJR.13.10597

89. Devaraj A, Wells AU, Meister MG, Corte TJ, Hansell DM. The effect of diffuse pulmonary fibrosis on the reliability of CT signs of pulmonary hypertension. Radiology. (2008) 249:1042-9. doi: 10.1148/radiol.2492080269

90. Tan RT, Kuzo R, Goodman LR, Siegel R, Haasler GB, Presberg KW. Utility of CT scan evaluation for predicting pulmonary hypertension in patients with parenchymal lung disease. Medical College of Wisconsin Lung Transplant Group. Chest. (1998) 113:1250-6

91. Devaraj A, Hansell DM. Computed tomography signs of pulmonary hypertension: old and new observations. Clin Radiol. (2009) 64:751-60. doi: 10.1016/j.crad.2008.12.005

92. Mahammedi A, Oshmyansky A, Hassoun PM, Thiemann DR, Siegelman SS. Pulmonary artery measurements in pulmonary hypertension: the role of computed tomography. J Thorac Imaging. (2013) 28:96-103. doi: 10.1097/RTI.0b013e318271c2eb

93. Kuriyama K, Gamsu G, Stern RG, Cann CE, Herfkens RJ, Brundage BH. CT-determined pulmonary artery diameters in predicting pulmonary hypertension. Invest Radiol. (1984) 19:16-22

94. Murray TI, Boxt LM, Katz J, Reagan K, Barst RJ. Estimation of pulmonary artery pressure in patients with primary pulmonary hypertension by quantitative analysis of magnetic resonance images. $J$ Thorac Imaging. (1994) 9:198-204

95. Ng CS, Wells AU, Padley SP. A CT sign of chronic pulmonary arterial hypertension: the ratio of main pulmonary artery to aortic diameter. $J$ Thorac Imaging. (1999) 14:270-8

96. Devaraj A, Wells AU, Meister MG, Corte TJ, Wort SJ, Hansell DM. Detection of pulmonary hypertension with multidetector CT and echocardiography alone and in combination. Radiology. (2010) 254:609-16. doi: 10.1148/radiol.09090548

97. Revel MP, Faivre JB, Remy-Jardin M, Delannoy-Deken V, Duhamel A, Remy J. Pulmonary hypertension: ECG-gated 64-section CT angiographic evaluation of new functional parameters as diagnostic criteria. Radiology. (2009) 250:558-66. doi: 10.1148/radiol.2502080315

98. Kawut SM, Silvestry FE, Ferrari VA, DeNofrio D, Axel L, Loh E, et al. Extrinsic compression of the left main coronary artery by the pulmonary artery in patients with long-standing pulmonary hypertension. Am J Cardiol. (1999) 83:984-6, A10

99. Dakkak W, Tonelli AR. Compression of adjacent anatomical structures by pulmonary artery dilation. Postgrad Med. (2016) 128:451-9. doi: 10.1080/00325481.2016.1157442

100. Mesquita SM, Castro CR, Ikari NM, Oliveira SA, Lopes AA. Likelihood of left main coronary artery compression based on pulmonary trunk diameter in patients with pulmonary hypertension. Am J Med. (2004) 116:369-74. doi: 10.1016/j.amjmed.2003.11.015

101. Demkow M, Kalinczuk L, Kepka C, Kurzyna M, Torbicki A. Left main artery compression by pulmonary artery aneurysm and ostial athero-stenosis of left anterior descending artery in a young female with pulmonary arterial hypertension. Eur Heart J. (2012) 33:2621. doi: 10.1093/eurheartj/ehs195

102. Abel E, Jankowski A, Pison C, Luc Bosson J, Bouvaist H, Ferretti GR. Pulmonary artery and right ventricle assessment in pulmonary hypertension: correlation between functional parameters of ECG-gated CT and right-side heart catheterization. Acta Radiol. (2012) 53:720-7. doi: 10.1258/ar.2012.120009

103. Reid JH, Murchison JT. Acute right ventricular dilatation: a new helical CT sign of massive pulmonary embolism. Clin Radiol. (1998) 53:694-8.

104. Baque-Juston MC, Wells AU, Hansell DM. Pericardial thickening or effusion in patients with pulmonary artery hypertension: a CT study. AJR Am J Roentgenol. (1999) 172:361-4. doi: 10.2214/ajr.172.2.9930782

105. van der Meer RW, Pattynama PM, van Strijen MJ, van den Berg-Huijsmans AA, Hartmann IJ, Putter $\mathrm{H}$, et al. Right ventricular dysfunction and pulmonary obstruction index at helical CT: prediction of clinical outcome during 3-month follow-up in patients with acute pulmonary embolism. Radiology. (2005) 235:798-803. doi: 10.1148/radiol.2353040593

106. Groves AM, Win T, Charman SC, Wisbey C, Pepke-Zaba J, Coulden RA. Semi-quantitative assessment of tricuspid regurgitation on contrast-enhanced multidetector CT. Clin Radiol. (2004) 59:715-9. doi: 10.1016/j.crad.2004.02.007

107. Chan AL, Juarez MM, Shelton DK, MacDonald T, Li CS, Lin TC, et al. Novel computed tomographic chest metrics to detect pulmonary hypertension. BMC Med Imaging. (2011) 11:7. doi: 10.1186/1471-2342-11-7

108. Rich JD, Ward RP. Right-ventricular function by nuclear cardiology. Curr Opin Cardiol. (2010) 25:445-50. doi: 10.1097/HCO.0b013e32833cb252

109. Knaapen P, van Campen LM, de Cock CC, Gotte MJ, Visser CA, Lammertsma AA, et al. Effects of cardiac resynchronization therapy on myocardial perfusion reserve. Circulation. (2004) 110:646-51. doi: 10.1161/01.CIR.0000138108687.19.C1

110. Wong YY, Raijmakers P, van Campen J, van der Laarse WJ, Knaapen $\mathrm{P}$, Lubberink $\mathrm{M}$, et al. 11C-Acetate clearance as an index of oxygen consumption of the right myocardium in idiopathic pulmonary arterial hypertension: a validation study using 15O-labeled tracers and PET. J Nucl Med. (2013) 54:1258-62. doi: 10.2967/jnumed.112.115915

111. Wong YY, Ruiter G, Lubberink M, Raijmakers PG, Knaapen P, Marcus JT, et al. Right ventricular failure in idiopathic pulmonary arterial hypertension is associated with inefficient myocardial oxygen utilization. Circ Heart Fail. (2011) 4:700-6. doi: 10.1161/CIRCHEARTFAILURE.111.962381

112. Crawley SF, Johnson MK, Dargie HJ, Peacock AJ. LA volume by CMR distinguishes idiopathic from pulmonary hypertension due to HFpEF. JACC Cardiovasc Imaging. (2013) 6:1120-1. doi: 10.1016/j.jcmg.2013.05.014

113. Helderman F, Mauritz GJ, Andringa KE, Vonk-Noordegraaf A, Marcus JT. Early onset of retrograde flow in the main pulmonary artery is a characteristic of pulmonary arterial hypertension. J Magn Reson Imaging. (2011) 33:13628. doi: 10.1002/jmri.22581

114. Condliffe R, Radon M, Hurdman J, Davies C, Hill C, Akil M, et al. CT pulmonary angiography combined with echocardiography in suspected systemic sclerosis-associated pulmonary arterial hypertension. Rheumatology. (2011) 50:1480-6. doi: 10.1093/rheumatology/ ker114

115. Rajaram S, Swift AJ, Capener D, Elliot CA, Condliffe R, Davies C, et al. Comparison of the diagnostic utility of cardiac magnetic resonance imaging, computed tomography, and echocardiography in assessment of suspected pulmonary arterial hypertension in patients with connective tissue disease. J Rheumatol. (2012) 39:1265-74. doi: 10.3899/jrheum.110987

116. Cottin V, Plauchu H, Bayle JY, Barthelet M, Revel D, Cordier JF. Pulmonary arteriovenous malformations in patients with hereditary hemorrhagic telangiectasia. Am J Respir Crit Care Med. (2004) 169:994-1000. doi: 10.1164/rccm.200310-14410C

117. Cottin V, Chinet T, Lavole A, Corre R, Marchand E, Reynaud-Gaubert M, et al. Pulmonary arteriovenous malformations in hereditary hemorrhagic telangiectasia: a series of 126 patients. Medicine (Baltimore). (2007) 86:1-17. doi: 10.1097/MD.0b013e31802f8da1

118. Remy J, Remy-Jardin M, Wattinne L, Deffontaines C. Pulmonary arteriovenous malformations: evaluation with CT of the chest before and after treatment. Radiology. (1992) 182:809-16. doi: 10.1148/radiology.182.3.1535899 
119. Junqueira FP, Lima CM, Coutinho AC, Jr., Parente DB, Bittencourt LK, Bessa LG, et al. Pulmonary arterial hypertension: an imaging review comparing MR pulmonary angiography and perfusion with multidetector CT angiography. Br J Radiol. (2012) 85:1446-56. doi: 10.1259/bjr/28150079

120. Fang JC, DeMarco T, Givertz MM, Borlaug BA, Lewis GD, Rame JE, et al. World Health Organization Pulmonary Hypertension group 2: pulmonary hypertension due to left heart disease in the adult-a summary statement from the Pulmonary Hypertension Council of the International Society for Heart and Lung Transplantation. J Heart Lung Transplant. (2012) 31:913-33. doi: 10.1016/j.healun.2012.06.002

121. Bradlow WM, Gibbs JS, Mohiaddin RH. Cardiovascular magnetic resonance in pulmonary hypertension. J Cardiovasc Magn Reson. (2012) 14:6. doi: 10.1186/1532-429X-14-6

122. Kam JC, Pi J, Doraiswamy V, Elnahar Y, Abdul-Jawad S, DeBari VA, et al. CT scanning in the evaluation of pulmonary hypertension. Lung. (2013) 191:321-6. doi: 10.1007/s00408-013-9464-6

123. Huis In 't Veld AE, Van Vliet AG, Spruijt OA, Handoko ML, Marcus JT, Vonk Noordegraaf A, et al. CTA-derived left to right atrial size ratio distinguishes between pulmonary hypertension due to heart failure and idiopathic pulmonary arterial hypertension. Int J Cardiol. (2016) 223:723-8. doi: 10.1016/j.ijcard.2016.08.314

124. Mets OM, Schmidt M, Buckens CF, Gondrie MJ, Isgum I, Oudkerk M, et al. Diagnosis of chronic obstructive pulmonary disease in lung cancer screening Computed Tomography scans: independent contribution of emphysema, air trapping and bronchial wall thickening. Respir Res. (2013) 14:59. doi: 10.1186/1465-9921-14-59

125. Schroeder JD, McKenzie AS, Zach JA, Wilson CG, Curran-Everett D, Stinson DS, et al. Relationships between airflow obstruction and quantitative CT measurements of emphysema, air trapping, and airways in subjects with and without chronic obstructive pulmonary disease. Am J Roentgenol. (2013) 201:W460-70. doi: 10.2214/AJR.12.10102

126. Coxson HO, Rogers RM, Whittall KP, D'Yachkova Y, Pare PD, Sciurba FC, et al. A quantification of the lung surface area in emphysema using computed tomography. Am J Respir Crit Care Med. (1999) 159:851-6. doi: 10.1164/ajrccm.159.3.9805067

127. Madani A, Zanen J, de Maertelaer V, Gevenois PA. Pulmonary emphysema: objective quantification at multi-detector row CT-comparison with macroscopic and microscopic morphometry. Radiology. (2006) 238:1036-43. doi: 10.1148/radiol.2382042196

128. Galban CJ, Han MK, Boes JL, Chughtai KA, Meyer CR, Johnson TD, et al. Computed tomography-based biomarker provides unique signature for diagnosis of COPD phenotypes and disease progression. Nat Med. (2012) 18:1711-5. doi: 10.1038/nm.2971

129. Martinez CH, Chen YH, Westgate PM, Liu LX, Murray S, Curtis JL, et al. Relationship between quantitative CT metrics and health status and BODE in chronic obstructive pulmonary disease. Thorax. (2012) 67:399-406. doi: 10.1136/thoraxjnl-2011-201185

130. Mohamed Hoesein FA, de Jong PA, Lammers JW, Mali WP, Mets OM, Schmidt M, et al. Contribution of CT quantified emphysema, air trapping and airway wall thickness on pulmonary function in male smokers with and without COPD. COPD. (2014) 11:503-9. doi: 10.3109/15412555.2014.933952

131. Iyer AS, Wells JM, Vishin S, Bhatt SP, Wille KM, Dransfield MT. CT scan-measured pulmonary artery to aorta ratio and echocardiography for detecting pulmonary hypertension in severe COPD. Chest. (2014) 145:82432. doi: 10.1378/chest.13-1422

132. Yazdani M, Lau CT, Lempel JK, Yadav R, El-Sherief AH, Azok JT, et al. Historical evolution of imaging techniques for the evaluation of pulmonary embolism. Radiographics. (2015) 35:1245-62. doi: 10.1148/rg.2015140280

133. Pengo V, Lensing AW, Prins MH, Marchiori A, Davidson BL, Tiozzo $\mathrm{F}$, et al. Incidence of chronic thromboembolic pulmonary hypertension after pulmonary embolism. N Engl J Med. (2004) 350:2257-64. doi: 10.1056/NEJMoa032274

134. He J, Fang W, Lv B, He JG, Xiong CM, Liu ZH, et al. Diagnosis of chronic thromboembolic pulmonary hypertension: comparison of ventilation/perfusion scanning and multidetector computed tomography pulmonary angiography with pulmonary angiography. Nucl Med Commun. (2012) 33:459-63. doi: 10.1097/MNM.0b013e32835 085d9
135. Galie N, Hoeper MM, Humbert M, Torbicki A, Vachiery JL, Barbera JA, et al. Guidelines for the diagnosis and treatment of pulmonary hypertension: the Task Force for the Diagnosis and Treatment of Pulmonary Hypertension of the European Society of Cardiology (ESC) and the European Respiratory Society (ERS), endorsed by the International Society of Heart and Lung Transplantation (ISHLT). Eur Heart J. (2009) 30:2493-537. doi: 10.1093/eurheartj/ehp297

136. D'Armini AM. Diagnostic advances and opportunities in chronic thromboembolic pulmonary hypertension. Eur Respir Rev. (2015) 24:253-62. doi: 10.1183/16000617.00000915

137. Resten A, Maitre S, Humbert M, Sitbon O, Capron F, Simoneau G, et al. Pulmonary arterial hypertension: thin-section CT predictors of epoprostenol therapy failure. Radiology. (2002) 222:782-8. doi: 10.1148/radiol.2223010668

138. Schembri GP, Miller AE, Smart R. Radiation dosimetry and safety issues in the investigation of pulmonary embolism. Semin Nucl Med. (2010) 40:44254. doi: 10.1053/j.semnuclmed.2010.07.007

139. Jenkins D, Mayer E, Screaton N, Madani M. State-of-the-art chronic thromboembolic pulmonary hypertension diagnosis and management. Eur Respir Rev. (2012) 21:32-9. doi: 10.1183/09059180.00009211

140. Liu M, Miao R, Guo X, Zhu L, Zhang H, Hou Q, et al. Saddle Pulmonary Embolism: Laboratory and Computed Tomographic Pulmonary Angiographic Findings to Predict Short-term Mortality. Heart Lung Circ. (2017) 26:134-42. doi: 10.1016/j.hlc.2016. 02.019

141. Reichelt A, Hoeper MM, Galanski M, Keberle M. Chronic thromboembolic pulmonary hypertension: evaluation with 64-detector row CT versus digital substraction angiography. Eur J Radiol. (2009) 71:49-54. doi: 10.1016/j.ejrad.2008.03.016

142. Auger WR, Kerr KM, Kim NH, Fedullo PF. Evaluation of patients with chronic thromboembolic pulmonary hypertension for pulmonary endarterectomy. Pulm Circ. (2012) 2:155-62. doi: 10.4103/2045-8932.97594

143. Liu M, Ma Z, Guo X, Zhang H, Yang Y, Wang C. Computed tomographic pulmonary angiography in the assessment of severity of chronic thromboembolic pulmonary hypertension and right ventricular dysfunction. Eur J Radiol. (2011) 80:e462-9. doi: 10.1016/j.ejrad.2010.08.035

144. Qanadli SD, El Hajjam M, Vieillard-Baron A, Joseph T, Mesurolle B, Oliva VL, et al. New CT index to quantify arterial obstruction in pulmonary embolism: comparison with angiographic index and echocardiography. AJR Am J Roentgenol. (2001) 176:1415-20. doi: 10.2214/ajr.176.6.1761415

145. Mastora I, Remy-Jardin M, Masson P, Galland E, Delannoy V, Bauchart JJ, et al. Severity of acute pulmonary embolism: evaluation of a new spiral CT angiographic score in correlation with echocardiographic data. Eur Radiol. (2003) 13:29-35. doi: 10.1007/s00330-002-1515-y

146. Liu M, Ma Z, Guo X, Chen X, Yang Y, Wang C. Cardiovascular parameters of computed tomographic pulmonary angiography to assess pulmonary vascular resistance in patients with chronic thromboembolic pulmonary hypertension. Int J Cardiol. (2013) 164:295-300. doi: 10.1016/j.ijcard.2011.07.019

147. Rajaram S, Swift AJ, Telfer A, Hurdman J, Marshall H, Lorenz E, et al. $3 \mathrm{D}$ contrast-enhanced lung perfusion MRI is an effective screening tool for chronic thromboembolic pulmonary hypertension: results from the ASPIRE Registry. Thorax. (2013) 68:677-8. doi: 10.1136/thoraxjnl-2012-203020

148. Forfia PR, Fisher MR, Mathai SC, Housten-Harris T, Hemnes AR, Borlaug BA, et al. Tricuspid annular displacement predicts survival in pulmonary hypertension. Am J Respir Crit Care Med. (2006) 174:1034-41. doi: 10.1164/rccm.200604-547OC

149. Bustamante-Labarta M, Perrone S, De La Fuente RL, Stutzbach P, De La Hoz RP, Torino A, et al. Right atrial size and tricuspid regurgitation severity predict mortality or transplantation in primary pulmonary hypertension. $J$ Am Soc Echocardiogr. (2002) 15(10 Pt 2):1160-4

150. Raymond RJ, Hinderliter AL, Willis PW, Ralph D, Caldwell EJ, Williams W, et al. Echocardiographic predictors of adverse outcomes in primary pulmonary hypertension. J Am Coll Cardiol. (2002) 39:1214-9. doi: 10.1016/ S0735-1097(02)01744-8

151. Mahapatra S, Nishimura RA, Oh JK, McGoon MD. The prognostic value of pulmonary vascular capacitance determined by Doppler echocardiography in patients with pulmonary arterial hypertension. J Am Soc Echocardiogr. (2006) 19:1045-50. doi: 10.1016/j.echo.2006.03.008 
152. Borges AC, Knebel F, Eddicks S, Panda A, Schattke S, Witt C, et al. Right ventricular function assessed by two-dimensional strain and tissue Doppler echocardiography in patients with pulmonary arterial hypertension and effect of vasodilator therapy. Am J Cardiol. (2006) 98:530-4. doi: 10.1016/j.amjcard.2006.02.060

153. van de Veerdonk MC, Kind T, Marcus JT, Mauritz GJ, Heymans MW, Bogaard HJ, et al. Progressive right ventricular dysfunction in patients with pulmonary arterial hypertension responding to therapy. J Am Coll Cardiol. (2011) 58:2511-9. doi: 10.1016/j.jacc.2011.06.068

154. Freed BH, Gomberg-Maitland M, Chandra S, Mor-Avi V, Rich S, Archer $\mathrm{SL}$, et al. Late gadolinium enhancement cardiovascular magnetic resonance predicts clinical worsening in patients with pulmonary hypertension. $J$ Cardiovasc Magn Reson. (2012) 14:11. doi: 10.1186/1532-429X-14-11

155. Gan CT, Lankhaar JW, Westerhof N, Marcus JT, Becker A, Twisk JW, et al. Noninvasively assessed pulmonary artery stiffness predicts mortality in pulmonary arterial hypertension. Chest. (2007) 132:1906-12. doi: 10.1378/chest.07-1246

156. Bossone E, D'Andrea A, D'Alto M, Citro R, Argiento P, Ferrara F, et al. Echocardiography in pulmonary arterial hypertension: from diagnosis to prognosis. J Am Soc Echocardiogr. (2013) 26:1-14. doi: 10.1016/j.echo.2012.10.009

157. D'Alto M, Romeo E, Argiento P, Di Salvo G, Badagliacca R, Cirillo AP, et al. Pulmonary arterial hypertension: the key role of echocardiography. Echocardiography. (2015) 32 (Suppl. 1):S23-37. doi: 10.1111/echo.12283

158. Batal O, Dardari Z, Costabile C, Gorcsan J, Arena VC, Mathier MA. Prognostic value of pericardial effusion on serial echocardiograms in pulmonary arterial hypertension. Echocardiography. (2015) 32:1471-6. doi: 10.1111/echo.12909

159. D’Alonzo GE, Barst RJ, Ayres SM, Bergofsky EH, Brundage BH, Detre $\mathrm{KM}$, et al. Survival in patients with primary pulmonary hypertension. Results from a national prospective registry. Ann Intern Med. (1991) 115: 343-9.

160. Thenappan T, Shah SJ, Rich S, Tian L, Archer SL, Gomberg-Maitland M. Survival in pulmonary arterial hypertension: a reappraisal of the NIH risk stratification equation. Eur Respir J. (2010) 35:1079-87. doi: 10.1183/09031936.00072709

161. Swift AJ, Wild JM, Nagle SK, Roldan-Alzate A, Francois CJ, Fain $\mathrm{S}$, et al. Quantitative magnetic resonance imaging of pulmonary hypertension: a practical approach to the current state of the art. J Thorac Imaging. (2014) 29:68-79. doi: 10.1097/RTI.000000000 0000079

162. Gan CT, Holverda S, Marcus JT, Paulus WJ, Marques KM, Bronzwaer JG, et al. Right ventricular diastolic dysfunction and the acute effects of sildenafil in pulmonary hypertension patients. Chest. (2007) 132:11-7. doi: $10.1378 /$ chest.06-1263

163. van Wolferen SA, van de Veerdonk MC, Mauritz GJ, Jacobs W, Marcus JT, Marques KMJ, et al. Clinically significant change in stroke volume in pulmonary hypertension. Chest. (2011) 139:1003-9. doi: 10.1378/chest.10-1066

164. Blyth KG, Groenning BA, Mark PB, Martin TN, Foster JE, Steedman $\mathrm{T}$, et al. NT-proBNP can be used to detect right ventricular systolic dysfunction in pulmonary hypertension. Eur Respir J. (2007) 29:737-44. doi: 10.1183/09031936.00095606

165. Ohno Y, Hatabu H, Murase K, Higashino T, Nogami M, Yoshikawa T, et al. Primary pulmonary hypertension: 3D dynamic perfusion MRI for quantitative analysis of regional pulmonary perfusion. AJR Am J Roentgenol. (2007) 188:48-56. doi: 10.2214/AJR.05.0135

166. Ohno Y, Murase K, Higashino T, Nogami M, Koyama H, Takenaka $\mathrm{D}$, et al. Assessment of bolus injection protocol with appropriate concentration for quantitative assessment of pulmonary perfusion by dynamic contrast-enhanced MR imaging. J Magn Reson Imaging. (2007) 25:55-65. doi: 10.1002/jmri.20790

167. Grunig E, Barner A, Bell M, Claussen M, Dandel M, Dumitrescu D, et al. Non-invasive diagnosis of pulmonary hypertension: ESC/ERS guidelines with updated commentary of the cologne consensus conference 2011. Int J Cardiol. (2011) 154 (Suppl 1):S3-12. doi: 10.1016/S0167-5273(11)70488-0

168. Sanchez O, Trinquart L, Colombet I, Durieux P, Huisman MV, Chatellier $\mathrm{G}$, et al. Prognostic value of right ventricular dysfunction in patients with haemodynamically stable pulmonary embolism: a systematic review. Eur Heart J. (2008) 29:1569-77. doi: 10.1093/eurheartj/ehn208

169. Baldi F, Fuso L, Arrighi E, Valente S. Optimal management of pulmonary arterial hypertension: prognostic indicators to determine treatment course. Ther Clin Risk Manag. (2014) 10:825-39. doi: 10.2147/TCRM.S48920

170. Galie N, Hinderliter AL, Torbicki A, Fourme T, Simonneau G, Pulido T, et al. Effects of the oral endothelin-receptor antagonist bosentan on echocardiographic and doppler measures in patients with pulmonary arterial hypertension. J Am Coll Cardiol. (2003) 41:1380-6 doi: 10.1016/S07351097(03)00121-9

171. Reesink HJ, Marcus JT, Tulevski, II, Jamieson S, Kloek JJ, Vonk Noordegraaf A, et al. Reverse right ventricular remodeling after pulmonary endarterectomy in patients with chronic thromboembolic pulmonary hypertension: utility of magnetic resonance imaging to demonstrate restoration of the right ventricle. $J$ Thorac Cardiovasc Surg. (2007) 133:58-64. doi: 10.1016/j.jtcvs.2006. 09.032

172. Grunig E, Tiede H, Enyimayew EO, Ehlken N, Seyfarth HJ, Bossone E, et al. Assessment and prognostic relevance of right ventricular contractile reserve in patients with severe pulmonary hypertension. Circulation. (2013) 128:2005-15. doi: 10.1161/CIRCULATIONAHA.113.0 01573

173. Tonelli AR, Conci D, Tamarappoo BK, Newman J, Dweik RA. Prognostic value of echocardiographic changes in patients with pulmonary arterial hypertension receiving parenteral prostacyclin therapy. $J$ Am Soc Echocardiogr. (2014) 27:733-41 e2. doi: 10.1016/j.echo.2014 .03 .012

174. McLaughlin VV, Gaine SP, Howard LS, Leuchte HH, Mathier MA, Mehta S, et al. Treatment goals of pulmonary hypertension. J Am Coll Cardiol. (2013) 62(25 Suppl):D73-81. doi: 10.1016/j.jacc.2013.10.034

175. Grothues F, Smith GC, Moon JC, Bellenger NG, Collins P, Klein HU, et al. Comparison of interstudy reproducibility of cardiovascular magnetic resonance with two-dimensional echocardiography in normal subjects and in patients with heart failure or left ventricular hypertrophy. Am J Cardiol. (2002) 90:29-34. doi: 10.1016/S0002-9149(02)02381-0

176. Wilkins MR, Paul GA, Strange JW, Tunariu N, Gin-Sing W, Banya WA, et al. Sildenafil versus Endothelin Receptor Antagonist for Pulmonary Hypertension (SERAPH) study. Am $J$ Respir Crit Care Med. (2005) 171:1292-7. doi: 10.1164/rccm.2004101411OC

177. Peacock AJ, Crawley S, McLure L, Blyth K, Vizza CD, Poscia R, et al. Changes in right ventricular function measured by cardiac magnetic resonance imaging in patients receiving pulmonary arterial hypertension-targeted therapy: the EURO-MR study. Circ Cardiovasc Imaging. (2014) 7:107-14. doi: 10.1161/CIRCIMAGING.113.000629

178. McCann GP, Beek AM, Vonk-Noordegraaf A, van Rossum AC. Delayed contrast-enhanced magnetic resonance imaging in pulmonary arterial hypertension. Circulation. (2005) 112:e268. doi: 10.1161/CIRCULATIONAHA.104.512848

179. Trip P, Kind T, van de Veerdonk MC, Marcus JT, de Man FS, Westerhof $\mathrm{N}$, et al. Accurate assessment of load-independent right ventricular systolic function in patients with pulmonary hypertension. J Heart Lung Transplant. (2013) 32:50-5. doi: 10.1016/j.healun.2012. 09.022

180. Kreitner KF, Wirth GM, Krummenauer F, Weber S, Pitton MB, Schneider J, et al. Noninvasive assessment of pulmonary hemodynamics in patients with chronic thromboembolic pulmonary hypertension by high temporal resolution phase-contrast MRI: correlation with simultaneous invasive pressure recordings. Circ Cardiovasc Imaging. (2013) 6:722-9. doi: 10.1161/CIRCIMAGING.112.000276

181. Jardim C, Rochitte CE, Humbert M, Rubenfeld G, Jasinowodolinski $\mathrm{D}$, Carvalho CR, et al. Pulmonary artery distensibility in pulmonary arterial hypertension: an MRI pilot study. Eur Respir J. (2007) 29:476-81. doi: $10.1183 / 09031936.00016806$

182. Resten A, Maitre S, Humbert M, Rabiller A, Sitbon O, Capron F, et al. Pulmonary hypertension: CT of the chest in pulmonary venoocclusive disease. AJR Am J Roentgenol. (2004) 183:65-70. doi: 10.2214/ajr.183.1.1830065 
183. Frazier AA, Franks TJ, Mohammed TL, Ozbudak IH, Galvin JR. From the Archives of the AFIP: pulmonary veno-occlusive disease and pulmonary capillary hemangiomatosis. Radiographics. (2007) 27:867-82. doi: 10.1148/rg.273065194

184. Fedullo PF, Auger WR, Kerr KM, Rubin LJ. Chronic thromboembolic pulmonary hypertension. $N$ Engl $J$ Med. (2001) 345:1465-72. doi: 10.1056/NEJMra010902

185. Tonelli AR, Ahmed M, Hamed F, Prieto LR. Peripheral pulmonary artery stenosis as a cause of pulmonary hypertension in adults. Pulm Circ. (2015) 5:204-10. doi: 10.1086/679727

186. Kauczor HU, Schwickert HC, Mayer E, Schweden F, Schild HH, Thelen M. Spiral CT of bronchial arteries in chronic thromboembolism. J Comput Assist Tomogr. (1994) 18:855-61

187. Nogami M, Ohno Y, Koyama H, Kono A, Takenaka D, Kataoka T, et al. Utility of phase contrast MR imaging for assessment of pulmonary flow and pressure estimation in patients with pulmonary hypertension: comparison with right heart catheterization and echocardiography. J Magn Reson Imaging. (2009) 30:973-80. doi: 10.1002/jmri.21935

188. Haeck ML, Scherptong RW, Marsan NA, Holman ER, Schalij MJ, Bax JJ, et al. Prognostic value of right ventricular longitudinal peak systolic strain in patients with pulmonary hypertension. Circ Cardiovasc Imaging. (2012) 5:628-36. doi: 10.1161/CIRCIMAGING.111.971465

189. Leibundgut G, Rohner A, Grize L, Bernheim A, Kessel-Schaefer A, Bremerich J, et al. Dynamic assessment of right ventricular volumes and function by real-time three-dimensional echocardiography: a comparison study with magnetic resonance imaging in 100 adult patients. J Am Soc Echocardiogr. (2010) 23:116-26. doi: 10.1016/j.echo.2009.11.016

190. Sachdev A, Villarraga HR, Frantz RP, McGoon MD, Hsiao JF, Maalouf JF, et al. Right ventricular strain for prediction of survival in patients with pulmonary arterial hypertension. Chest. (2011) 139:1299-309. doi: 10.1378/chest.10-2015

191. Shehata ML, Harouni AA, Skrok J, Basha TA, Boyce D, Lechtzin N, et al. Regional and global biventricular function in pulmonary arterial hypertension: a cardiac MR imaging study. Radiology. (2013) 266:114-22. doi: 10.1148/radiol.12111599

192. Garcia-Alvarez A, Garcia-Lunar I, Pereda D, Fernandez-Jimenez R, SanchezGonzalez J, Mirelis JG, et al. Association of myocardial T1-mapping CMR with hemodynamics and RV performance in pulmonary hypertension. JACC Cardiovasc Imaging. (2015) 8:76-82. doi: 10.1016/j.jcmg.201 4.08.012

193. Tatebe S, Fukumoto Y, Oikawa-Wakayama M, Sugimura K, Satoh K, Miura Y, et al. Enhanced [18F]fluorodeoxyglucose accumulation in the right ventricular free wall predicts long-term prognosis of patients with pulmonary hypertension: a preliminary observational study. Eur Heart $J$ Cardiovasc Imaging. (2014) 15:666-72. doi: 10.1093/ehjci/jet276

194. Kreitner KF. Noninvasive imaging of pulmonary hypertension. Semin Respir Crit Care Med. (2014) 35:99-111. doi: 10.1055/s-0033-1363456

195. Gerges M, Gerges C, Lang IM. Advanced imaging tools rather than hemodynamics should be the primary approach for diagnosing, following, and managing pulmonary arterial hypertension. Can J Cardiol. (2015) 31:521-8. doi: 10.1016/j.cjca.2015.01.019

196. Greiner S, Andre F, Heimisch M, Hess A, Steen H, Katus HA, et al. Non-invasive quantification of right ventricular systolic function by echocardiography: a new semi-automated approach. Clin Res Cardiol. (2013) 102:229-35. doi: 10.1007/s00392-012-0528-Z

197. Grapsa J, O’Regan DP, Pavlopoulos H, Durighel G, Dawson D, Nihoyannopoulos P. Right ventricular remodelling in pulmonary arterial hypertension with three-dimensional echocardiography: comparison with cardiac magnetic resonance imaging. Eur J Echocardiogr. (2010) 11:64-73. doi: 10.1093/ejechocard/jep169

198. Vitarelli A, Mangieri E, Terzano C, Gaudio C, Salsano F, Rosato E, et al. Three-dimensional echocardiography and 2D-3D speckle-tracking imaging in chronic pulmonary hypertension: diagnostic accuracy in detecting hemodynamic signs of right ventricular (RV) failure. J Am Heart Assoc. (2015) 4:e001584. doi: 10.1161/JAHA.114.001584

199. Biswas S, Ananthasubramaniam K. Clinical utility of three-dimensional echocardiography for the evaluation of ventricular function. Cardiol Rev. (2013) 21:184-95. doi: 10.1097/CRD.0b013e3182815af2
200. Bossone E, Rubenfire M, Bach DS, Ricciardi M, Armstrong WF. Range of tricuspid regurgitation velocity at rest and during exercise in normal adult men: implications for the diagnosis of pulmonary hypertension. J Am Coll Cardiol. (1999) 33:1662-6.

201. Grunig E, Weissmann S, Ehlken N, Fijalkowska A, Fischer C, Fourme $\mathrm{T}$, et al. Stress Doppler echocardiography in relatives of patients with idiopathic and familial pulmonary arterial hypertension: results of a multicenter European analysis of pulmonary artery pressure response to exercise and hypoxia. Circulation. (2009) 119:1747-57. doi: 10.1161/CIRCULATIONAHA.108.800938

202. Shehata ML, Cheng S, Osman NF, Bluemke DA, Lima JA. Myocardial tissue tagging with cardiovascular magnetic resonance. J Cardiovasc Magn Reson. (2009) 11:55. doi: 10.1186/1532-429X-11-55

203. Moore CC, Lugo-Olivieri CH, McVeigh ER, Zerhouni EA. Threedimensional systolic strain patterns in the normal human left ventricle: characterization with tagged MR imaging. Radiology. (2000) 214:453-66. doi: 10.1148/radiology.214.2.r00fe17453

204. Mauritz GJ, Vonk-Noordegraaf A, Kind T, Surie S, Kloek JJ, Bresser P, et al. Pulmonary endarterectomy normalizes interventricular dyssynchrony and right ventricular systolic wall stress. J Cardiovasc Magn Reson. (2012) 14:5. doi: $10.1186 / 1532-429 \mathrm{X}-14-5$

205. Wirth G, Bruggemann K, Bostel T, Mayer E, Duber C, Kreitner KF. Chronic thromboembolic pulmonary hypertension (CTEPH) - potential role of multidetector-row CT (MD-CT) and MR imaging in the diagnosis and differential diagnosis of the disease. Rofo. (2014) 186:751-61. doi: 10.1055/s-0034-1366425

206. Spruijt OA, Vissers L, Bogaard HJ, Hofman MB, Vonk-Noordegraaf A, Marcus JT. Increased native T1-values at the interventricular insertion regions in precapillary pulmonary hypertension. Int J Cardiovasc Imaging. (2016) 32:451-9. doi: 10.1007/s10554-015-0787-7

207. Holverda S, Gan CT, Marcus JT, Postmus PE, Boonstra A, VonkNoordegraaf A. Impaired stroke volume response to exercise in pulmonary arterial hypertension. J Am Coll Cardiol. (2006) 47:1732-3. doi: 10.1016/j.jacc.2006.01.048

208. Naeije R, Vanderpool R, Dhakal BP, Saggar R, Saggar R, Vachiery JL, et al. Exercise-induced pulmonary hypertension: physiological basis and methodological concerns. Am J Respir Crit Care Med. (2013) 187:576-83. doi: 10.1164/rccm.201211-2090CI

209. Schafer M, Barker AJ, Kheyfets V, Stenmark KR, Crapo J, Yeager ME, et al. Helicity and vorticity of pulmonary arterial flow in patients with pulmonary hypertension: quantitative analysis of flow formations. J Am Heart Assoc. (2017) 6:e007010. doi: 10.1161/JAHA.117.007010

210. Dawes TJW, de Marvao A, Shi W, Fletcher T, Watson GMJ, Wharton J, et al. Machine learning of three-dimensional right ventricular motion enables outcome prediction in pulmonary hypertension: a cardiac MR imaging study. Radiology. (2017) 283:381-90. doi: 10.1148/radiol.2016161315

211. Ohno Y, Koyama H, Yoshikawa T, Seki S, Takenaka D, Yui M, et al. Pulmonary high-resolution ultrashort TE MR imaging: Comparison with thin-section standard- and low-dose computed tomography for the assessment of pulmonary parenchyma diseases. J Magn Reson Imaging. (2016) 43:512-32. doi: 10.1002/jmri.25008

212. Ameli-Renani S, Rahman F, Nair A, Ramsay L, Bacon JL, Weller A, et al. Dual-energy CT for imaging of pulmonary hypertension: challenges and opportunities. Radiographics. (2014) 34:1769-90. doi: 10.1148/rg.347130085

213. Hachulla AL, Lador F, Soccal PM, Montet X, Beghetti M. Dualenergy computed tomographic imaging of pulmonary hypertension. Swiss Med Wkly. (2016) 146:w14328. doi: 10.4414/smw.2016. 14328

214. Nakazawa T, Watanabe Y, Hori Y, Kiso K, Higashi M, Itoh T, et al. Lung perfused blood volume images with dual-energy computed tomography for chronic thromboembolic pulmonary hypertension: correlation to scintigraphy with single-photon emission computed tomography. J Comput Assist Tomogr. (2011) 35:590-5. doi: 10.1097/RCT.0b013e3182 $24 \mathrm{e} 227$

215. Ameli-Renani S, Ramsay L, Bacon JL, Rahman F, Nair A, Smith V, et al. Dual-energy computed tomography in the assessment of vascular and parenchymal enhancement in suspected pulmonary hypertension. J Thorac Imaging. (2014) 29:98-106. doi: 10.1097/RTI.0000000000000061 
216. Dournes G, Verdier D, Montaudon M, Bullier E, Riviere A, Dromer $\mathrm{C}$, et al. Dual-energy CT perfusion and angiography in chronic thromboembolic pulmonary hypertension: diagnostic accuracy and concordance with radionuclide scintigraphy. Eur Radiol. (2014) 24:42-51. doi: 10.1007/s00330-013-2975-y

217. Meinel FG, Graef A, Thierfelder KM, Armbruster M, Schild C, Neurohr $\mathrm{C}$, et al. Automated quantification of pulmonary perfused blood volume by dual-energy CTPA in chronic thromboembolic pulmonary hypertension. Rofo. (2014) 186:151-6. doi: 10.1055/s-0033-1350412

218. Hong YJ, Kim JY, Choe KO, Hur J, Lee HJ, Choi BW, et al. Different perfusion pattern between acute and chronic pulmonary thromboembolism: evaluation with two-phase dual-energy perfusion CT. AJR Am J Roentgenol. (2013) 200:812-7. doi: 10.2214/AJR.12.8697

219. Petretta M, Costanzo P, Acampa W, Imbriaco M, Ferro A, Filardi PP, et al. Noninvasive assessment of coronary anatomy and myocardial perfusion: going toward an integrated imaging approach. J Cardiovasc Med (Hagerstown). (2008) 9:977-86. doi: 10.2459/JCM.0b013e3283 06f311

220. Kawakami T, Kataoka M, Nakahara T, Yamada Y, Takei M, Jinzaki M, et al. Usefulness of 3D SPECT/CT fusion image in CTEPH. Int J Cardiol. (2015) 194:39-40. doi: 10.1016/j.ijcard.2015.05.056

221. Lysenkov M, Ansheles AA, Ivanov KP, Martyniuk TV, Sergienko VB. [Diagnostic capabilities of single-photon emission computed tomography/computed tomography in the evaluation of perfusion disorders in pulmonary hypertension]. Vestn Rentgenol Radiol. (2013) (6):26-31.

222. Lau EM, Bailey DL, Bailey EA, Torzillo PJ, Roach PJ, Schembri GP, et al. Pulmonary hypertension leads to a loss of gravity dependent redistribution of regional lung perfusion: a SPECT/CT study. Heart. (2014) 100:47-53. doi: 10.1136/heartjnl-2013-304254

223. Soler X, Hoh CK, Test VJ, Kerr KM, Marsh JJ, Morris TA. Single photon emission computed tomography in chronic thromboembolic pulmonary hypertension. Respirology. (2011) 16:131-7. doi: 10.1111/j.1440-1843.2010.01867.x

224. Heller GV. Practical issues regarding the incorporation of PET into a busy SPECT practice. J Nucl Cardiol. (2012) 19 (Suppl. 1):S12-8. doi: $10.1007 /$ s12350-011-9493-6
225. Oikawa M, Kagaya Y, Otani H, Sakuma M, Demachi J, Suzuki J, et al. Increased [18F]fluorodeoxyglucose accumulation in right ventricular free wall in patients with pulmonary hypertension and the effect of epoprostenol. J Am Coll Cardiol. (2005) 45:1849-55. doi: 10.1016/j.jacc.200 5.02 .065

226. Fang W, Zhao L, Xiong CM, Ni XH, He ZX, He JG, et al. Comparison of 18 F-FDG uptake by right ventricular myocardium in idiopathic pulmonary arterial hypertension and pulmonary arterial hypertension associated with congenital heart disease. Pulm Circ. (2012) 2:365-72. doi: 10.4103/2045-8932.101651

227. Ahmadi A, Ohira H, Mielniczuk LM. FDG PET imaging for identifying pulmonary hypertension and right heart failure. Curr Cardiol Rep. (2015) 17:555. doi: 10.1007/s11886-014-0555-7

228. van de Veerdonk MC, Marcus JT, Bogaard HJ, Vonk Noordegraaf A. State of the art: advanced imaging of the right ventricle and pulmonary circulation in humans (2013 Grover Conference series). Pulm Circ. (2014) 4:158-68. doi: $10.1086 / 675978$

229. Nensa F, Poeppel TD, Beiderwellen K, Schelhorn J, Mahabadi AA, Erbel R, et al. Hybrid PET/MR imaging of the heart: feasibility and initial results. Radiology. (2013) 268:366-73. doi: 10.1148/radiol.131 30231

Disclaimer: The views expressed in this article are those of the authors and do not necessarily reflect the position or policy of the Department of Veterans Affairs or the United States Government.

Conflict of Interest Statement: The authors declare that the research was conducted in the absence of any commercial or financial relationships that could be construed as a potential conflict of interest.

Copyright (c) 2019 Hur and Sugeng. This is an open-access article distributed under the terms of the Creative Commons Attribution License (CC BY). The use, distribution or reproduction in other forums is permitted, provided the original author(s) and the copyright owner(s) are credited and that the original publication in this journal is cited, in accordance with accepted academic practice. No use, distribution or reproduction is permitted which does not comply with these terms. 